\title{
Observation of mesospheric air inside the arctic stratospheric polar vortex in early 2003
}

\author{
A. Engel ${ }^{1}$, T. Möbius ${ }^{1}$, H.-P. Haase ${ }^{1,}{ }^{*}$, H. Bönisch ${ }^{1}$, T. Wetter ${ }^{1}$, U. Schmidt ${ }^{1}$, I. Levin ${ }^{2}$, T. Reddmann ${ }^{3}$, H. Oelhaf ${ }^{3}$,

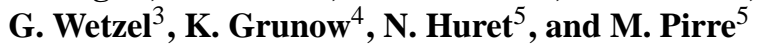 \\ ${ }^{1}$ Institut für Atmosphäre und Umwelt, J. W. Goethe Universität Frankfurt, Frankfurt, Germany \\ ${ }^{2}$ Institut für Umweltphysik, Ruprecht - Karls Universität Heidelberg, Heidelberg, Germany \\ ${ }^{3}$ Institut für Meteorologie und Klimaforschung, Forschungszentrum Karlsruhe, Karlsruhe, Germany \\ ${ }^{4}$ Institut für Meteorologie, Freie Universität Berlin, Berlin, Germany \\ ${ }^{5}$ Laboratoire de Physique et Chimie de l'Environnement, CNRS and Université d'Orléans, Orléans, France \\ *now at: DEKA Bank, Frankfurt, Germany
}

Received: 18 July 2005 - Published in Atmos. Chem. Phys. Discuss.: 26 August 2005

Revised: 12 December 2005 - Accepted: 13 December 2005 - Published: 1 February 2006

\begin{abstract}
During several balloon flights inside the Arctic polar vortex in early 2003, unusual trace gas distributions were observed, which indicate a strong influence of mesospheric air in the stratosphere. The tuneable diode laser (TDL) instrument SPIRALE (Spectroscopie Infra-Rouge par Absorption de Lasers Embarqués) measured unusually high CO values (up to $600 \mathrm{ppb}$ ) on 27 January at about $30 \mathrm{~km}$ altitude. The cryosampler BONBON sampled air masses with very high molecular Hydrogen, extremely low $\mathrm{SF}_{6}$ and enhanced $\mathrm{CO}$ values on 6 March at about $25 \mathrm{~km}$ altitude. Finally, the MIPAS (Michelson Interferometer for Passive Atmospheric Sounding) Fourier Transform Infra-Red (FTIR) spectrometer showed $\mathrm{NO}_{\mathrm{y}}$ values which are significantly higher than $\mathrm{NO}_{\mathrm{y}} *$ (the $\mathrm{NO}_{\mathrm{y}}$ derived from a correlation between $\mathrm{N}_{2} \mathrm{O}$ and $\mathrm{NO}_{\mathrm{y}}$ under undisturbed conditions), on 21 and 22 March in a layer centred at $22 \mathrm{~km}$ altitude. Thus, the mesospheric air seems to have been present in a layer descending from about $30 \mathrm{~km}$ in late January to $25 \mathrm{~km}$ altitude in early March and about $22 \mathrm{~km}$ altitude on 20 March. We present corroborating evidence from a model study using the KASIMA (KArlsruhe SImulation model of the Middle Atmosphere) model that also shows a layer of mesospheric air, which descended into the stratosphere in November and early December 2002, before the minor warming which occurred in late December 2002 lead to a descent of upper stratospheric air, cutting off a layer in which mesospheric air is present. This layer then descended inside the vortex over the course of the winter. The same feature is found in trajectory calculations, based on a large number of trajectories started in the vicinity of the observations on 6 March. Based on the difference between the mean age derived from $\mathrm{SF}_{6}$ (which has an irreversible meso-
\end{abstract}

Correspondence to: A. Engel

(an.engel@meteor.uni-frankfurt.de) spheric loss) and from $\mathrm{CO}_{2}$ (whose mesospheric loss is much smaller and reversible) we estimate that the fraction of mesospheric air in the layer observed on 6 March, must have been somewhere between $35 \%$ and $100 \%$.

\section{Introduction}

Diabatic descent inside the stratospheric polar wintertime vortices of both hemispheres is a well known phenomenon which can be diagnosed based on tracer observations (e.g. Bauer et al., 1994; Greenblatt et al., 2002; Podolske et al., 1989). This downward transport is part of the large scale Brewer Dobson circulation. Due to the relative isolation of the air masses inside the vortices, the descending air masses conserve many of their characteristics. The origin of the air masses descending into the polar vortex is therefore important when determining their chemical properties. Some observations show that air can also descend from the mesosphere into the polar stratospheric vortex (e.g. Fisher et al., 1993; Kouker et al., 1995; Ray et al., 2002; Rinsland et al., 1999), which is supported by modelling studies (e.g. Plumb et al., 2002; Siskind et al., 1997).

As mesospheric air has a different chemical composition in comparison to stratospheric air, it is important to know how much air is descending from the mesosphere into the stratospheric polar vortex for a quantitative understanding of stratospheric chemistry. Due to reactions taking place in the thermosphere and upper mesosphere, mesospheric air is enhanced in reactive nitrogen compounds (e.g. Solomon et al., 1985), which can effect ozone (e.g. Konopka et al., $2006^{1}$ ). Furthermore, mesospheric air is enhanced in CO

\footnotetext{
${ }^{1}$ Konopka, P., Engel, A., Funke, B., Müller, R., Grooß, J. U.,
} 
(Lopez-Valverde et al., 1996) and is expected to show enhanced levels of molecular hydrogen and depleted values of water vapour, which may influence the chemistry of $\mathrm{OH}$ radicals.

Many studies have used changes in correlations between ozone and long lived tracers to quantify ozone depletion inside the polar vortex, especially in the distorted northern hemispheric vortex (see, e.g. Proffitt et al., 1990; Müller et al., 1997, 2001). These studies assume an initial correlation (usually observed in early winter or late fall, i.e. before the onset of any heterogeneous activation of chlorine compounds) and then evaluate the change in this correlation with time to infer chemical ozone depletion. Plumb et al. (2000) showed that mixing of air masses with different origin can lead to changes in correlations which are caused by dynamics, not by chemistry. If mesospheric air is transported into the polar vortex in significant amounts, air masses with a very different chemical fingerprint and also a different relationship between ozone and long lived tracers may influence the stratospheric composition. The maximum of the ozone mixing ratio is typically found in the upper stratosphere between 5 and $10 \mathrm{hPa}$, the mesosphere and upper stratosphere are characterised by decreasing ozone with altitude, in contrast to the middle stratosphere where ozone increases with altitude. Consequently, ozone and long lived tracers like e.g. $\mathrm{CH}_{4}$ or $\mathrm{N}_{2} \mathrm{O}$ should be correlated in the mesosphere, whereas they are anticorrelated with respect to each other in the lower and middle stratosphere. Any descent of mesospheric air into the stratosphere will consequently lead to a change in the correlation between ozone and long lived tracers. The effect of dynamical processes on the correlation between trace gases has been considered in some studies of ozone depletion (e.g. Müller et al., 2001). Changes in correlations have also been used to study denitrification inside the polar vortices (e.g. Fahey et al., 1990). Kondo et al. (1999) and Wetzel et al. (2002) were able to show that their observed anomalous correlation between $\mathrm{N}_{2} \mathrm{O}$ and $\mathrm{NO}_{\mathrm{y}}$ inside the polar vortex in February and March 1997 was indeed mainly caused by dynamical effects.

Downward transport of mesospheric air is, therefore, an important phenomenon which has a significant impact on the chemical composition of the polar stratosphere and is important in studies of ozone depletion as well (e.g. Konopka et al., 2006 ${ }^{1}$ ). As mentioned above, $\mathrm{CO}, \mathrm{H}_{2}$ and $\mathrm{NO}$ may be good tracers of mesospheric air for such studies. All of these tracers, however, have a limited lifetime. Mesospheric loss of $\mathrm{SF}_{6}$ has been evaluated by Ravishankara et al. (1993), Hall and Waugh (1998) and Reddmann et al. (2001), showing that $\mathrm{SF}_{6}$ has a mesospheric sink, which leads to a de-

\footnotetext{
Günther, G., Wetter, T., Stiller, G., von Clarmann, T., Glatthor, N., Oelhaf, H., Wetzel, G., Lopez-Puertas, M., Pirre, M., Huret, N., and Riese, M.: Ozone loss driven by nitrogen oxides and triggered by stratospheric warmings may outweigh the effect of halogens, Geophys. Res. Lett., in review, 2006.
}

crease of mixing ratios. $\mathrm{SF}_{6}$ and $\mathrm{CO}_{2}$ are both used as age tracers in studies of stratospheric transport. Several studies (Strunk et al., 2000; Andrews et al., 2001; Engel et al., 2002) show that mean age values derived from both tracers are very similar when the mean age is between about 2 and 5 years, whereas there is a slight tendency for $\mathrm{SF}_{6}$ derived mean age to be higher for older air samples. Such differences have indeed been observed inside the polar vortex (Ray et al., 2002; Plumb et al., 2002; Waugh and Hall, 2002) and at mid latitudes in air masses which where characterised as remnants of the polar vortex (Strunk et al., 2000; Waugh and Hall, 2002). In both cases the high mean age values derived from $\mathrm{SF}_{6}$ were attributed to the presence of mesospheric air. The mean age derived from $\mathrm{SF}_{6}$ observations and its difference from the mean age derived from $\mathrm{CO}_{2}$ are, therefore, also an indicator for the contribution of mesospheric air.

Here we present observations of tracers performed during a series of balloon flights launched from the ESRANGE balloon and rocket launch facility near Kiruna, Sweden $\left(67.8^{\circ} \mathrm{N}, 21.1^{\circ} \mathrm{E}\right)$ in early 2003 . All balloons where launched as part of the ENVISAT (ENVIronment SATellite) validation activities. Measurements of different tracers are presented, depending on the observational capabilities of the instruments on board the payloads. The species observed include tracers for which profile observations display specific mesospheric structures. We focus on observations with a balloon-borne cryogenic whole air sampler on 6 March 2003. These observations are used to diagnose the presence of mesospheric air in the stratosphere which must have been recently transported downward into the stratosphere. The data are interpreted using the KASIMA Model. We show that KASIMA can reproduce the observed differences in $\mathrm{SF}_{6}$ and $\mathrm{CO}_{2}$ derived mean age, as well as the vertical structure of the age distribution. Trajectory studies using the FUB (Free University of Berlin) Model and heating rates calculated for the actual situation also show the same features. They also show that above the layer of mesospheric air, a large fraction of the polar vortex air is of tropical origin, in agreement with the findings of Konopka et al. $(2006)^{1}$. The downward transport of mesospheric air is discussed in light of the meteorological situation. Finally we estimate the fraction of mesospheric air present in the stratospheric layer investigated.

\section{Characteristics of mesospheric air}

Mesospheric air has quite a different chemical composition compared to stratospheric air. This plays an important role when diagnosing transport and mixing from tracer observations and also has an impact on chemical processes. In general mesospheric air has higher mixing ratios of $\mathrm{CO}$ (e.g. Rinsland et al., 1999; Lopez-Valverde et al., 1996), NO (Siskind et al., 1997) and $\mathrm{H}_{2}$ (LeTexier et al., 1988) then stratospheric air, whereas water vapour is expected to show reduced levels in comparison to stratospheric air (Kouker et 
Table 1. Balloon flights performed during the winter 2002/2003 showing evidence of mesospheric air in the stratosphere. All balloons were launched from ESRANGE, near Kiruna, Sweden $\left(67.8^{\circ} \mathrm{N} / 21.1^{\circ} \mathrm{E}\right)$. All measurements showing mesospheric influence which are used here were performed inside of the polar vortex.

\begin{tabular}{|c|c|c|c|}
\hline Date & Instrument & Measurement principle & Mesospheric tracer \\
\hline 21 Jan 2003 & SPIRALE & IR Tuneable Diode Laser & CO, see Sect. 3.1 \\
\hline 6 March 2003 & BONBON on TRIPLE & Cryogenic whole air sampler & $\begin{array}{l}\mathrm{CO}, \mathrm{H}_{2} \text { and the difference } \\
\text { between } \mathrm{CO}_{2} \text { and } \mathrm{SF}_{6} \\
\text { derived mean age, see Sect. } 3.2\end{array}$ \\
\hline $\begin{array}{l}\text { 20 March } 2003 \\
\text { to } 21.3 .2003\end{array}$ & MIPAS-B2 & Emission FTIR spectrometer & $\begin{array}{l}\mathrm{NO}_{\mathrm{y}} \text { species vs. } \mathrm{NO}_{\mathrm{y}}^{*} \\
\text { calculated from measured } \mathrm{N}_{2} \mathrm{O} \text {, } \\
\text { see Sect. } 3.3\end{array}$ \\
\hline
\end{tabular}

al., 1995). Dissociation and ionisation reactions of molecular nitrogen are the source of $\mathrm{NO}$, whereas $\mathrm{CO}$ is produced from the photolysis of $\mathrm{CO}_{2}$. $\mathrm{NO}$ and $\mathrm{CO}$ have a rather similar chemistry in the mesosphere and lower thermosphere, as noted by Solomon et al. (1985). Both molecules have rather short lifetimes in the sunlit mesosphere and lower thermosphere due to reactions with atomic oxygen in the case of $\mathrm{CO}$ and photolysis in the case of NO. However, once they are transported into the dark high latitude winter atmosphere, their local lifetime increases, resulting in high mixing ratios in the wintertime mesosphere (Solomon et al., 1985; Siskind et al., 1997). Another tracer which shows significant differences between the stratosphere and the mesosphere is $\mathrm{SF}_{6}$. While no sink processes for $\mathrm{SF}_{6}$ are known in the stratosphere, it can be depleted in the mesosphere due to photolysis and electron attachment processes (see, e.g. Reddmann et al. (2001) for an overview of $\mathrm{SF}_{6}$ chemistry). This process may influence the age determination based on $\mathrm{SF}_{6}$ observations. The other age tracer often used in the stratosphere, $\mathrm{CO}_{2}$, also has a sink in the upper atmosphere, where its photolysis is the source of $\mathrm{CO}$. However, once air masses reach the stratosphere and the sunlit atmosphere the sink processes which yield $\mathrm{CO}$ should be reversible and $\mathrm{CO}_{2}$ should be reproduced by the reaction of $\mathrm{CO}$ with $\mathrm{OH}$ radicals. Mesospheric air should thus be recognizable by enhanced values of $\mathrm{NO}, \mathrm{CO}, \mathrm{H}_{2}$, lower values of water vapour and a difference in the mean age determined from $\mathrm{SF}_{6}$ and $\mathrm{CO}_{2}$, respectively. Of these different indicators of mesospheric influence CO should have the shortest chemical lifetime, as it is expected to return to its typical stratospheric mixing ratios on the order of about 10 to $20 \mathrm{ppb}$ within a few months. Molecular hydrogen has a somewhat longer chemical lifetime, whereas the difference in $\mathrm{SF}_{6}$ - and $\mathrm{CO}_{2}$-derived mean age should be conserved, except for dynamical mixing processes, which should tend to decrease the difference, when mesospheric air is mixed with stratospheric air. NO, another mesospheric tracer, will go into equilibrium with other nitrogen species in the stratosphere. The total amount of $\mathrm{NO}_{\mathrm{y}}$ should, however, stay enhanced. It should also be noted, that due to the different physical and chemical mechanisms these tracers are not expected to be representative of identical airmasses.

\section{Observations}

During the ENVISAT validation campaign, which was carried out from the ESRANGE Balloon and Rocket launch facility near Kiruna, Sweden $\left(67.8^{\circ} \mathrm{N}, 21.1^{\circ} \mathrm{E}\right)$, a series of balloon payloads was launched to measure a suite of chemical species. The measurements of mesospherically influenced air come from several different instruments. The instruments and the observations are described briefly below (see also Table 1).

\subsection{SPIRALE}

SPIRALE is a balloon-borne instrument providing simultaneous in-situ measurements of atmospheric species from the tropopause up to $40 \mathrm{~km}$ using tuneable laser diodes in the mid-infrared $(3 \mu \mathrm{m}$ to $10 \mu \mathrm{m})$. The six laser beams pass through a $3.5 \mathrm{~m}$ multipass Herriott cell located under the gondola. Eighty six reflections occur, giving a $300 \mathrm{~m}$ optical path. The instrument provides measurements with a vertical resolution of a few meters. Relative uncertainties on concentrations have been evaluated ( $3 \%$ for $\mathrm{CH}_{4}$ and $\mathrm{N}_{2} \mathrm{O}, 5 \%$ for $\mathrm{O}_{3}$ and $\mathrm{CO}$ and depending on altitude, 3 to $20 \%$ for $\mathrm{NO}_{2}, 5$ to $20 \%$ for $\mathrm{HNO}_{3}$ and 7 to $15 \%$ for $\mathrm{HCl}$ ). A detailed description of the instrument and its operating mode can be found in Moreau et al. (2005).

The SPIRALE gondola was launched from ESRANGE on 21 January 2003 and reached a ceiling altitude of nearly $32 \mathrm{~km}$. The observations presented were taken during the ascent of the balloon. In the lower part of the $\mathrm{N}_{2} \mathrm{O}$ profile a lot of structure is observed. Comparison with the two reference profiles shown in Fig. 1 suggests that the observations were partly inside and partly outside of the vortex or in the 

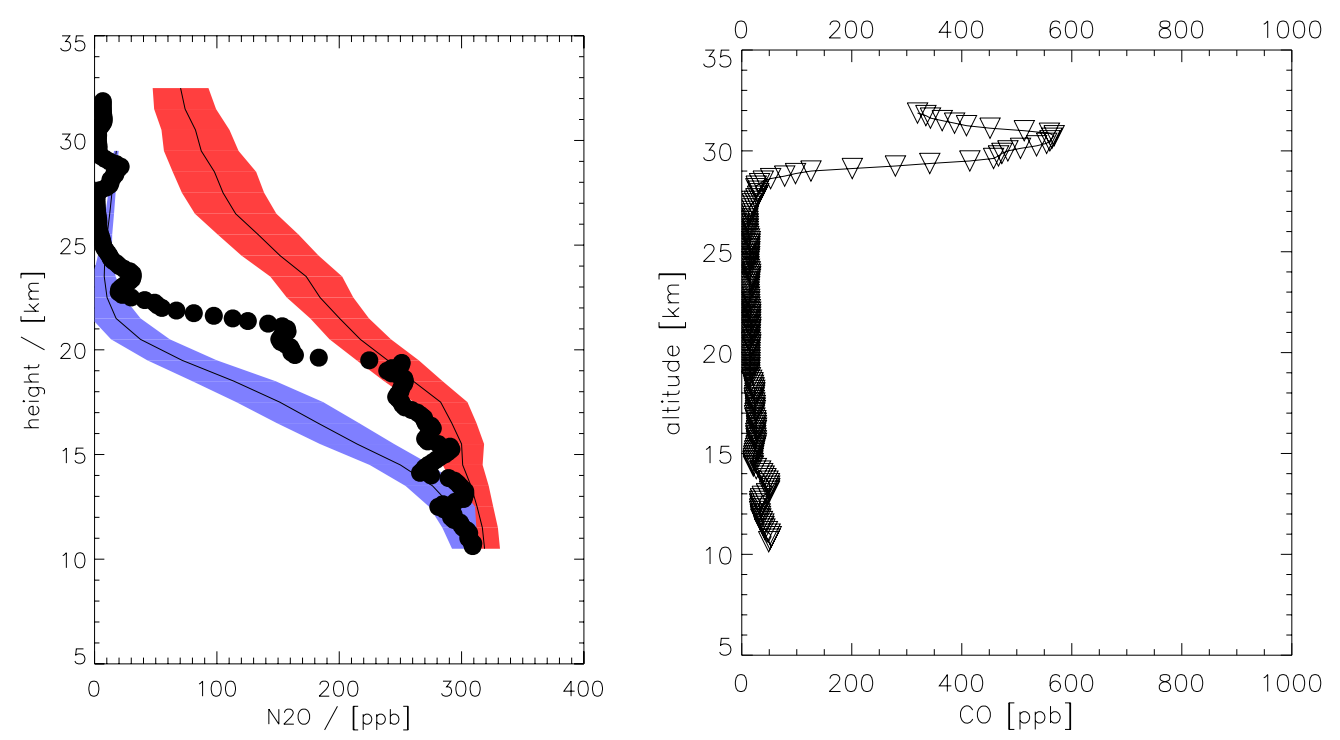

Fig. 1. Vertical profiles of selected trace gases observed on 21 January 2003 from Kiruna, Sweden $\left(68^{\circ}\right.$ N) by the SPIRALE TDL instrument. The left-hand panel shows the vertical profile of $\mathrm{N}_{2} \mathrm{O}$ plotted together with two mean profiles calculated from many observations at mid latitudes during summer/fall (red) and inside the polar vortex (blue). For the details of the mean profiles see Engel et al. (2002). The right-hand panel shows the vertical profile of $\mathrm{CO}$, which is extremely enhanced above $29 \mathrm{~km}$ altitude.

vortex edge region. This feature is confirmed by PV maps. Between 15 and $19 \mathrm{~km}$ altitude SPIRALE sampled outside vortex air as can be seen from the much higher $\mathrm{N}_{2} \mathrm{O}$ values than those of the reference profile. In this region the $\mathrm{N}_{2} \mathrm{O}$ values are close to the mid latitude reference profile. Above $20 \mathrm{~km}$ altitude there is a sharp decrease in $\mathrm{N}_{2} \mathrm{O}$ mixing ratios and above $22 \mathrm{~km}$ altitude the SPIRALE observations fall in the range of the reference profile for inside vortex conditions. The CO vertical distribution shows typical stratospheric values between 25 and $10 \mathrm{ppb}$ in the altitude range between 15 and $27 \mathrm{~km}$. Just above $27 \mathrm{~km}$ altitude, a sharp increase in $\mathrm{CO}$ mixing ratios is observed, with maximum values above $500 \mathrm{ppb}$ of $\mathrm{CO}$ in a layer between 30 and $31 \mathrm{~km}$ altitude. As explained above, enhanced $\mathrm{CO}$ values are typical of the high latitude winter mesosphere. E.g. ISAMS measurements in January 1992 showed values up to 4 ppm of CO in the high latitude winter mesosphere (Lopez-Valverde et al., 1996). The elevated $\mathrm{CO}$ is, therefore, a clear sign of mesospheric air in the stratosphere. The SPIRALE observations are discussed in detail in Huret et al. (2006).

\subsection{BONBON on TRIPLE}

TRIPLE is a multi-instrument payload carrying a cryogenic whole air sampler (BONBON) (Schmidt et al., 1987; Engel et al., 1997), a Chemical Conversion Resonance fluorescence instrument for the measurement of $\mathrm{ClO}$ and $\mathrm{BrO}$ (Woyke et al., 1999) and a Lyman- $\alpha$ hygrometer (FISH) (Zöger et al., 1999). The samples collected by BONBON are analysed for a large suite of trace gases, including the most promi- nent CFCs, $\mathrm{N}_{2} \mathrm{O}, \mathrm{CH}_{4}, \mathrm{H}_{2}, \mathrm{CO}, \mathrm{SF}_{6}$ and $\mathrm{CO}_{2}$. Most measurements are given relative to the NOAA/CMDL scale (e.g. Elkins et al., 1993; Conway et al., 1994), with the exception of $\mathrm{SF}_{6}$, which is given on the scale defined by Maiss and Levin (1994) and $\mathrm{CO}$ and $\mathrm{H}_{2}$ which are calibrated relative to a standard provided by the Oregon Graduate Institute (OGI) (Khalil and Rasmussen, 1988, 1990). As explained above, $\mathrm{H}_{2}, \mathrm{CO}$ and $\mathrm{SF}_{6}$ can be used to detect the influence of mesospheric air. The balloon was launched on 6 March 2003 when the polar vortex was well above Kiruna, and reached an altitude of more than $32 \mathrm{~km}$. Figure 2 shows the vertical distribution of $\mathrm{N}_{2} \mathrm{O}, \mathrm{H}_{2}, \mathrm{CO}$ and $\mathrm{SF}_{6} . \mathrm{N}_{2} \mathrm{O}$ shows a very steep vertical gradient, with mixing ratios falling below $5 \mathrm{ppb}$ above $22 \mathrm{~km}$, indicating that the samples were collected well inside of the polar vortex. Above this altitude there is a slow increase with altitude, with values at the top of the profile reaching between 18 and $19 \mathrm{ppb}$. $\mathrm{CO}$ and $\mathrm{H}_{2}$ show maximum values in a layer at an altitude of about $25 \mathrm{~km}$, i.e. several $\mathrm{km}$ above the minimum values of $\mathrm{N}_{2} \mathrm{O}$. In the same layer which shows high mixing ratios of $\mathrm{CO}$ and $\mathrm{H}_{2}$, a local minimum in $\mathrm{SF}_{6}$ is observed, whereas $\mathrm{CO}_{2}$ shows no significant structures in this region. Just below the maximum of $\mathrm{H}_{2}$, one sample shows particularly low values of $\mathrm{H}_{2}$. Such values are expected in the upper stratosphere near $50 \mathrm{~km}$ altitude, especially in the summer hemisphere, when the photochemical loss of $\mathrm{H}_{2}$ is at its maximum (LeTexier et al., 1988). However, the model used by LeTexier et al. (1988), also predicts a local minimum in $\mathrm{H}_{2}$ in the high latitude winter stratosphere (see their Fig. 8). 


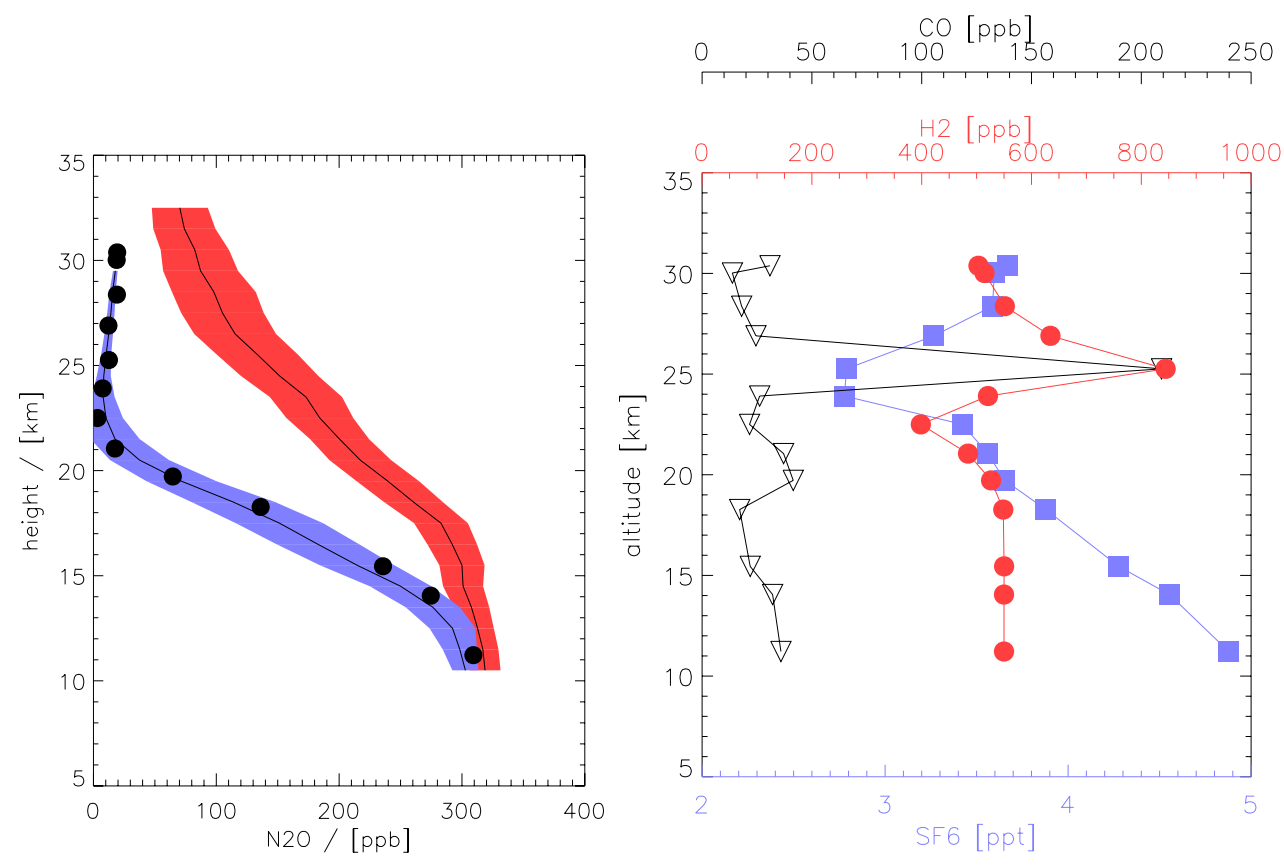

Fig. 2. Vertical profiles of selected trace gases observed on 6 March 2003 from Kiruna, Sweden $\left(68^{\circ} \mathrm{N}\right)$ by the BONBON whole air sampler instrument on the TRIPLE gondola. The left-hand panel shows the vertical profile of $\mathrm{N}_{2} \mathrm{O}$ plotted together with two mean profiles calculated from many observations at mid latitudes during summer/fall (red) and inside the polar vortex (blue). For the details of the mean profiles see Engel et al. (2002). Measured profiles of $\mathrm{CO}$ (black), $\mathrm{H}_{2}$ (red), and $\mathrm{SF}_{6}$ (blue), are shown on the right-hand panel.

\subsubsection{Mean age of air from $\mathrm{SF}_{6}$ and $\mathrm{CO}_{2}$ observations}

The observations of $\mathrm{SF}_{6}$ and $\mathrm{CO}_{2}$ were used to derive the mean age $(\Gamma)$ of air in the stratosphere, using tropospheric time series derived from $\mathrm{SF}_{6}$ observations by NOAA/CMDL (Geller et al., 1997, updated) and IUP Heidelberg (Maiss and Levin, 1994, updated) and $\mathrm{CO}_{2}$ measurements by NOAA/CMDL (Conway et al., 1994, updated). As a first approximation we have calculated the mean age using the formulas given in Volk et al. (1997), which requires a parameterisation of the width of the age spectrum $(\Delta)$ to correct for non-linearity in the tropospheric growth rates. We have used a time period of 15 years before the sampling date for the fit to the tropospheric data. The parameterisation of the width of the age spectrum $\left(\Delta=0.7 * \Gamma^{2}\right)$ was chosen as in Engel et al. (2002), which is based on Hall and Plumb (1994) and also showed most consistent results between our $\mathrm{CO}_{2}$ and $\mathrm{SF}_{6}$ derived mean age values. In a second step we have then used the estimated mean age value to explicitly calculate the Greens function describing the age spectrum, again using the same parameterisation for the width of the age spectrum, and integrating it in time, in order to determine the time interval over which one should fit in order to represent $98 \%$ of the tropospheric input. We then fitted a second order polynomial to the tropospheric reference data using this time period, which would cover $98 \%$ of the tropospheric input. Using this procedure, shorter fit intervals are used for low mean age val- ues, which leads to a better representation of the tropospheric data. As the non-linearity in the tropospheric time series of $\mathrm{CO}_{2}$ and $\mathrm{SF}_{6}$ are rather small, the differences between this procedure and the procedure used in Engel et al. (2002) are less than 0.5 years.

As noted above, $\mathrm{SF}_{6}$ can be irreversibly chemically destroyed in the mesosphere. While $\mathrm{CO}_{2}$ can also be photolysed in the upper mesosphere, this leads to the formation of $\mathrm{CO}$, which, further down in the atmosphere can be oxidised again to reform $\mathrm{CO}_{2}$. The observed enhanced mixing ratios of $\mathrm{CO}$ indicate that this may have happened, yet the effect is small, as the maximum $\mathrm{CO}$ value only reaches about $200 \mathrm{ppb}$, which corresponds to an error in the mean age derived from $\mathrm{CO}_{2}$ of less than 2 months. In the absence of loss processes, the age values derived from $\mathrm{SF}_{6}$ and $\mathrm{CO}_{2}$ are expected to agree within their error bars. Engel et al. (2002) showed that for several observations performed between 1997 and 2000 this was indeed true when mean ages ranged between 2 and 5 years. The mean age profiles obtained using $\mathrm{SF}_{6}$ and $\mathrm{CO}_{2}$ are compared in Fig. 3. There is a large difference in derived mean age around $25 \mathrm{~km}$ altitude, with $\mathrm{SF}_{6}$ derived mean age of more than 10 years, in contrast to the $\mathrm{CO}_{2}$ derived mean age, which shows values around 5 years, typical for stratospheric air at these altitudes (see, e.g. Engel et al., 2002). As the measured $\mathrm{SF}_{6}$ must be affected by chemical breakdown in the mesosphere, this 


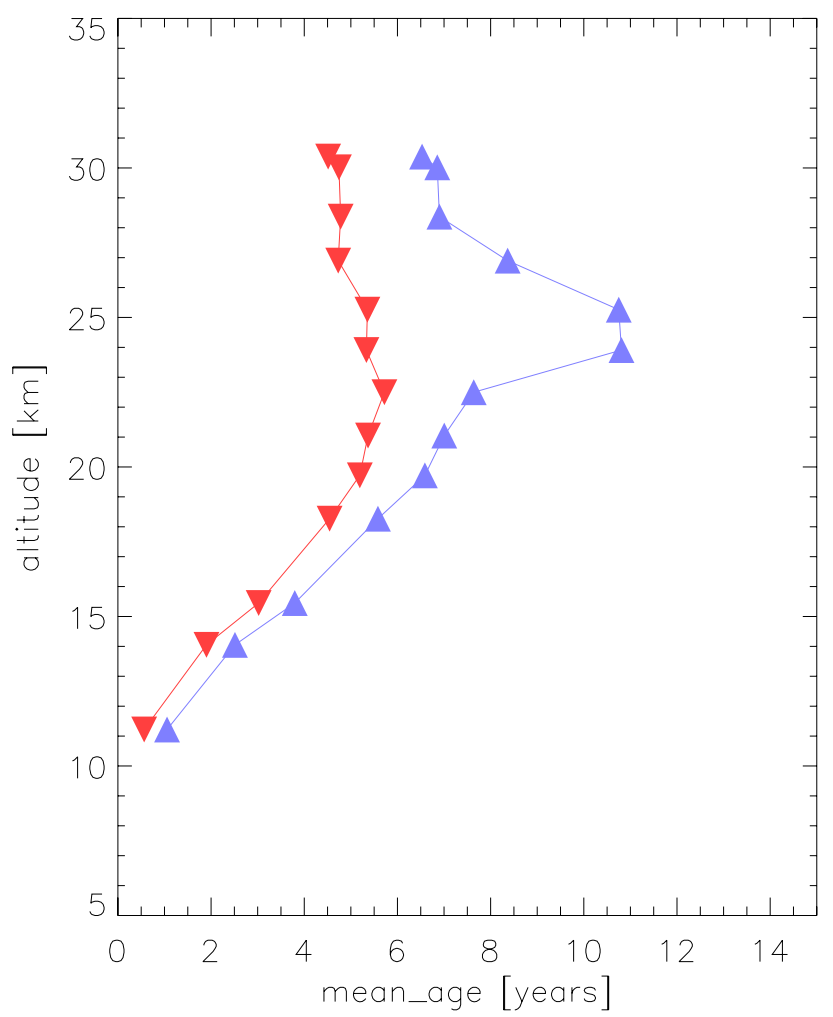

Fig. 3. Mean age of air calculated from $\mathrm{SF}_{6}$ (blue) and $\mathrm{CO}_{2}$ (red) for the vertical profiles observed on 6 March 2003, from Kiruna by the BONBON whole air sampler instrument on the TRIPLE gondola, see text for details.

$\mathrm{SF}_{6}$-based result does not represent a mean age equivalent to mean atmospheric transport times. In the following we will, therefore, call this term the apparent age. Note that the $\mathrm{CO}_{2}$ derived mean age and these $\mathrm{SF}_{6}$-derived apparent age values also show differences above and below this level, indicating that air masses above and below the layer at $25 \mathrm{~km}$ also have partly mesospheric characteristics.

\subsection{MIPAS-B}

MIPAS-B is an advanced cryogenic FTIR spectrometer specially tailored to the operation on a stratospheric balloon gondola (Friedl-Vallon et al., 2004). Equipped with suitable subsystems, MIPAS-B allows precise limb emission sounding of IR active atmospheric constituents. Vertical profiles of ozone and a considerable number of key radicals and reservoir species of the nitrogen, hydrogen, and chlorine families as well as source gases can be obtained simultaneously with an altitude resolution of 2 to $3 \mathrm{~km}$. Retrievals of trace gas profiles are performed with a non-linear least squares fitting procedure (Höpfner et al., 2002). The error estimation includes random noise as well as the mutual influence of the fitted parameters, temperature errors, line of sight (LOS) inaccuracies, and spectroscopic data errors. The precision of retrieved profiles is typically $3-7 \%$ and the accuracy reaches 7-15\% (see, e.g. Wetzel et al., 2002).

The MIPAS-B instrument was launched on 20 March 2003 from Kiruna. The balloon reached a ceiling altitude of $31 \mathrm{~km}$. Several series of limb scans were performed. The instrument can be adjusted in order to observe in a specified direction. Here we present results of a limb scan measured during the night (around 22:00 UT) when the instruments field of view was directed into the vortex. Figure 4 compares the $\mathrm{N}_{2} \mathrm{O}$ observations of MIPAS-B with our reference profiles. Over the entire altitude range there is a remarkable agreement. As with the in-situ observations from the cryogenic whole air sampler, the lowest values of $\mathrm{N}_{2} \mathrm{O}$ are not observed at the top of the profile but rather around 22 to $23 \mathrm{~km}$ altitude. In the same altitude layer, a marked difference between the $\mathrm{NO}_{\mathrm{y}}$ values (derived from the observed mixing ratios of $\mathrm{HNO}_{3}$, $\mathrm{ClONO}_{2}, \mathrm{NO}$ and $\mathrm{NO}_{2}$ ) and $\mathrm{NO}_{\mathrm{y}}{ }^{*}$, the expected $\mathrm{NO}_{\mathrm{y}}$ derived from a correlation between $\mathrm{N}_{2} \mathrm{O}$ and $\mathrm{NO}_{\mathrm{y}}$ under undisturbed polar winter conditions) is observed (Fig. 4, right hand panel). The difference is higher than could be explained by the error bars of the measurements. As noted above, NO is enhanced in the mesosphere. The presence of mesospheric air could thus explain the observed enhancement in $\mathrm{NO}_{\mathrm{y}}$ with respect to $\mathrm{NO}_{\mathrm{y}}{ }^{*}$.

\section{Model calculations and data intercomparison}

In order to investigate when the mesospheric air was transported into the stratosphere, we performed model calculations using the KASIMA model and trajectory calculations with the FUB model. In particular, we will use the apparent age derived from modelled and measured $\mathrm{SF}_{6}$ as a tracer of mesospheric air for the comparison.

\subsection{Model calculations}

The model experiments were made with the KASIMA model environment. A multi-annual run in a similar manner as described in Reddmann et al. (2001) was started in model year 1989. As meteorological input the ERA40 re-analysis and subsequent operational analyses were used up to $1 \mathrm{~Pa}$, using only the ECMWF temperature as a tendency term (see Kouker et al., 1999). Resolution was T21 in the horizontal corresponding to about $5 \mathrm{deg}$ in spherical coordinates, and $750 \mathrm{~m}$ in the vertical from $10 \mathrm{up}$ to $25 \mathrm{~km}$. Above $25 \mathrm{~km} \mathrm{lev-}$ els increase to about $3 \mathrm{~km}$ at $120 \mathrm{~km}$ pressure altitude, which is the top level of the model. From the eight different $\mathrm{SF}_{6}$ like chemical tracers described in Reddmann et al. (2001), the tracer $\mathrm{S} 3$, which describes a standard $\mathrm{SF}_{6}$ chemistry, was used to initialize a short-term transport experiment with a horizontal resolution of T63 (equivalent to about $2 \mathrm{deg}$ ) and a vertical resolution of $250 \mathrm{~m}$ up to $30 \mathrm{~km}$. The date of initialization was chosen to the day of the year (DOY) 340 in 2002. This tracer was transported as a completely inert tracer until 

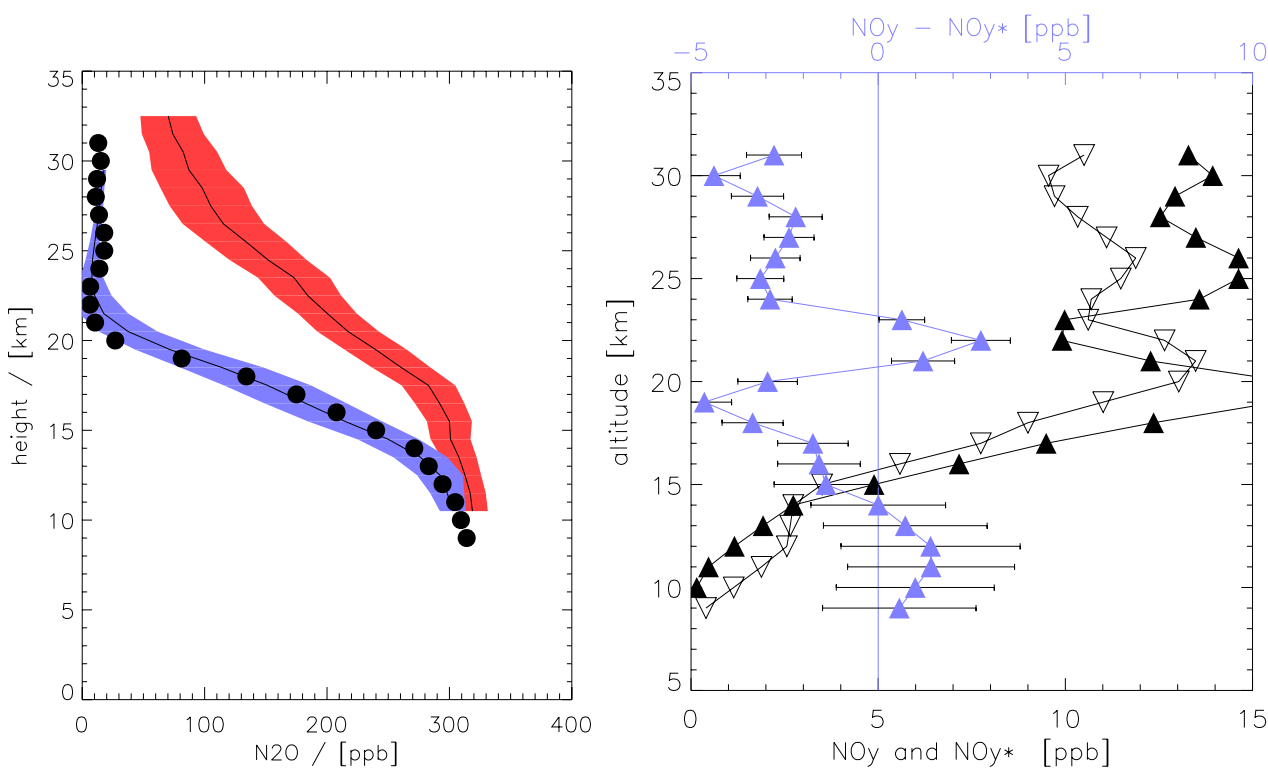

Fig. 4. Vertical profiles of selected trace gases observed on 20 March 2003 from Kiruna, Sweden $\left(68^{\circ}\right.$ N) by the MIPAS-B FTIR spectrometer. The left-hand panel shows the vertical profile of $\mathrm{N}_{2} \mathrm{O}$ plotted together with two mean profiles calculated from many observations at mid latitudes during summer/fall (red) and inside the polar vortex (blue). For details of the mean profiles see Engel et al. (2002). Note that the MIPAS-B profile agrees very well with our mean profile for inside vortex conditions. The right-hand panel shows the vertical profiles of $\mathrm{NO}_{\mathrm{y}}$ (open triangles), $\mathrm{NO}_{\mathrm{y}}$ * (closed triangles) and the difference between them (blue triangles). In the absence of de-/renitrification processes or anomalous mixing events, it is expected that this difference is close to zero. Note the significantly enhanced values of $\mathrm{NO}_{\mathrm{y}}$ in comparison to the $\mathrm{NO}_{\mathrm{y}}$ * expected from the $\mathrm{N}_{2} \mathrm{O}$ observation in the layer between 21 and $23 \mathrm{~km}$.

March 2003. Note, that the calculation of the tracer distribution in the model results from a 10 year run, where the model is about at equilibrium conditions.

\subsection{Comparison of models and observations}

Apparent age calculated from modelled $\mathrm{SF}_{6}$ is used as a mesospheric tracer in the KASIMA model. A direct comparison is only possible with the $\mathrm{SF}_{6}$ observation from 6 March 2003. Figure 5 shows the comparison of the BONBON observations with the KASIMA data for this date interpolated to the time and coordinates of the BONBON observations. The location of the mesospheric layer is very well reproduced. The apparent age values from the model (maximum of between 12 and 13 years) are a little higher than the observations (maximum about 11 years). This may be due either to the large uncertainties in the mesospheric chemistry of $\mathrm{SF}_{6}$ or to the integration which occurs during the collection of the samples. Similar comparisons with the mesospheric tracers observed during the other flights are shown in Figs. 6 and 7. On 21 January 2003 the sharp increase observed in the SPIRALE CO observations is not very well reproduced in the model. This could be due to the different sink region of $\mathrm{CO}$ and $\mathrm{SF}_{6}$ in the mesosphere, as a comparison with observed $\mathrm{CH} 4$ mixing ratios (not shown) shows quite similar vertical structure. For 20/21 March, KASIMA models the mesospheric layer at about $24 \mathrm{~km}$, which is about $1 \mathrm{~km}$ higher than was actually observed by MIPAS.

KASIMA is able to reproduce the layered structure observed on 6 March 2003 and 20/21 March 2003 and also produces the right order of magnitude in apparent age and the correct altitude range of the mesospherically influenced layer. We conclude that there is qualitatively good agreement between the KASIMA calculations and the balloon observations. On 6 March 2003, where a direct comparison is possible, there is also a good quantitative agreement.

\subsection{Temporal development of the mesospheric air intrusion}

From the observations of the SPIRALE instrument it is clear that mesospheric air was present in the stratosphere already in late January 2003. The SPIRALE observations also indicate a layered structure, as observed in the cryosampler and MIPAS-B results. It is thus likely that the observed mesospheric air was transported into the stratosphere already early during the winter. Figure 8 shows the vertical cross sections of the zonal mean of the apparent age derived from the KASIMA cacluations for the DOY 300-360 in 2002. Descent of high apparent age values is observed already around November. While an apparent age level of 10 years is observed only around $50 \mathrm{~km}$ altitude on day 300 (27 October), it has descended to around $42 \mathrm{~km}$ on day 320 (16 November) 


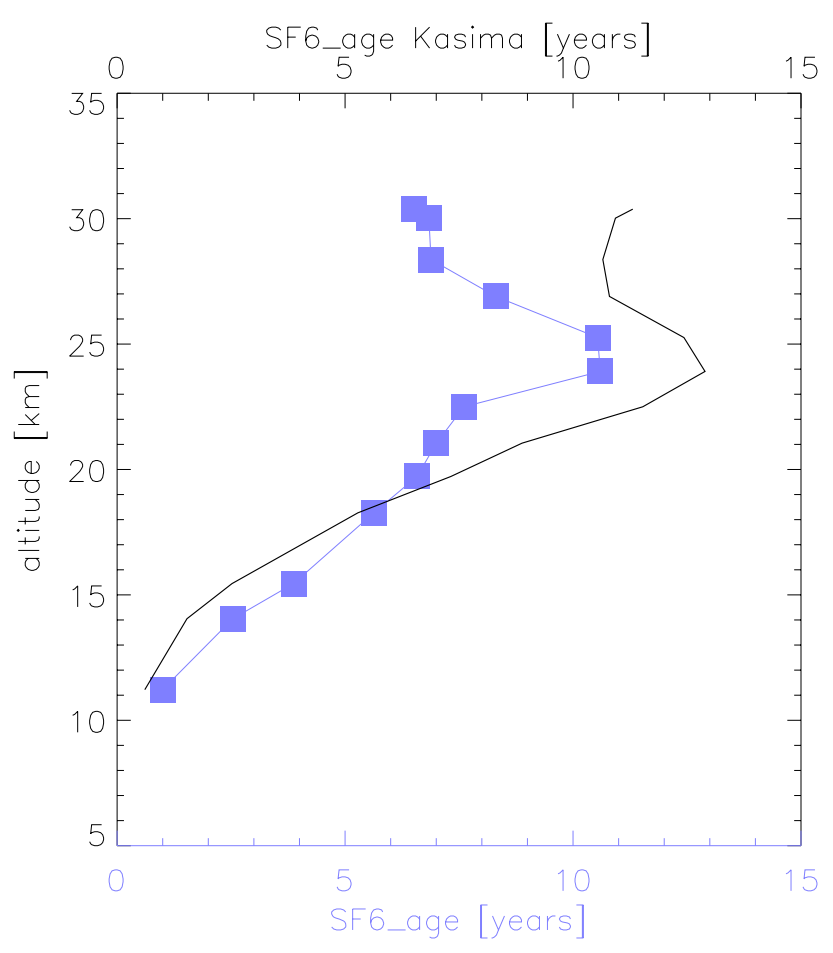

Fig. 5. Comparison of $\mathrm{SF}_{6}$ derived mean age from the KASIMA model (solid line) and from $\mathrm{SF}_{6}$ observed on 6 March by the cryogenic whole air sampler BONBON.

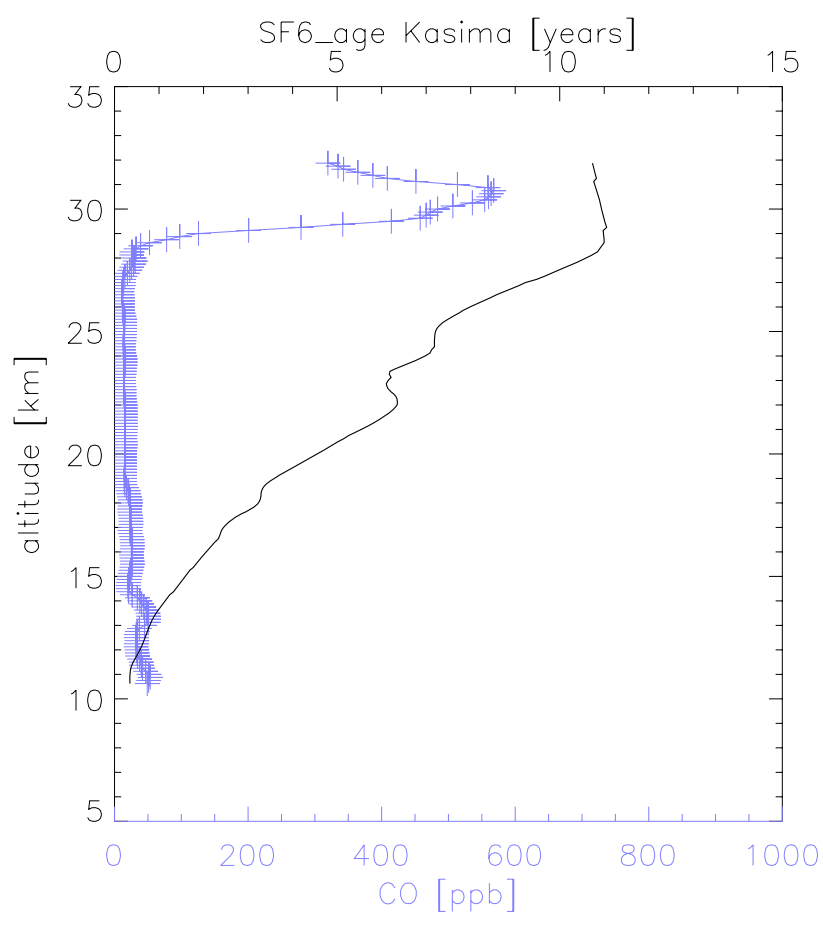

Fig. 6. Comparison of $\mathrm{SF}_{6}$ derived mean age from the KASIMA model (solid line) with CO observation by SPIRALE on 21 Januaray 2003 as tracer of mesospheric air. Note that $\mathrm{CO}$ has a different chemistry from $\mathrm{SF}_{6}$, so that no direct comparison is possible.

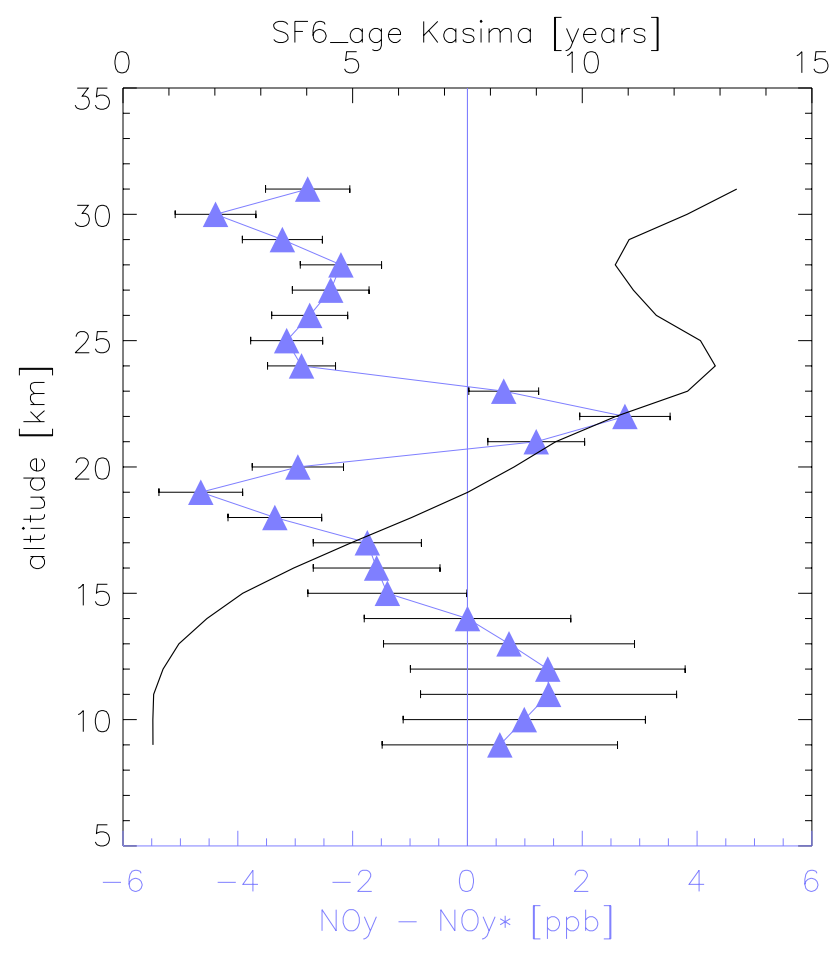

Fig. 7. Comparison of $\mathrm{SF}_{6}$ derived mean age from the KASIMA model (solid line) with differences between $\mathrm{NO}_{\mathrm{y}}$ and $\mathrm{NO}_{\mathrm{y}}$ * observations by MIPAS on 20 March 2003 as tracer of mesospheric air.

and to $35 \mathrm{~km}$ on day 340 (6 December). On day 360 (26 December) the model shows apparent age values of 10 years as low as $32 \mathrm{~km}$. At this time, however, there is a layer between about 40 and $50 \mathrm{~km}$ altitude, which shows lower, i.e. rather stratospheric values of apparent age, and which separates the regions influenced by mesospheric air above and below. This shows that air masses with more stratospheric character must have been transported polewards at this altitude level sometime during the second half of December.

The high resolution version of the model then conserves the layered structure which was produced in December 2002 during January, February and March 2003, while it is slowly being transported downwards by the descent inside of the vortex. By March 2003 (Fig. 5), the layer of mesospheric air in the model is transported down and is centered around 24-25 km altitude, with peak values of apparent age exceeding 10 years, as was observed by the cryogenic whole air sampler.

\subsection{Trajectory calculations with the FUB model}

Long term trajectory calculations were made with the FUB trajectory model (Reimer and Scherer, 1992). In the version used in this study, the model uses the ECMWF operational analyses as meteorological input up to $1 \mathrm{hPa}$. The ECMWF data are interpolated horizontally to a $1.25^{\circ} \times 1.25^{\circ}$ 

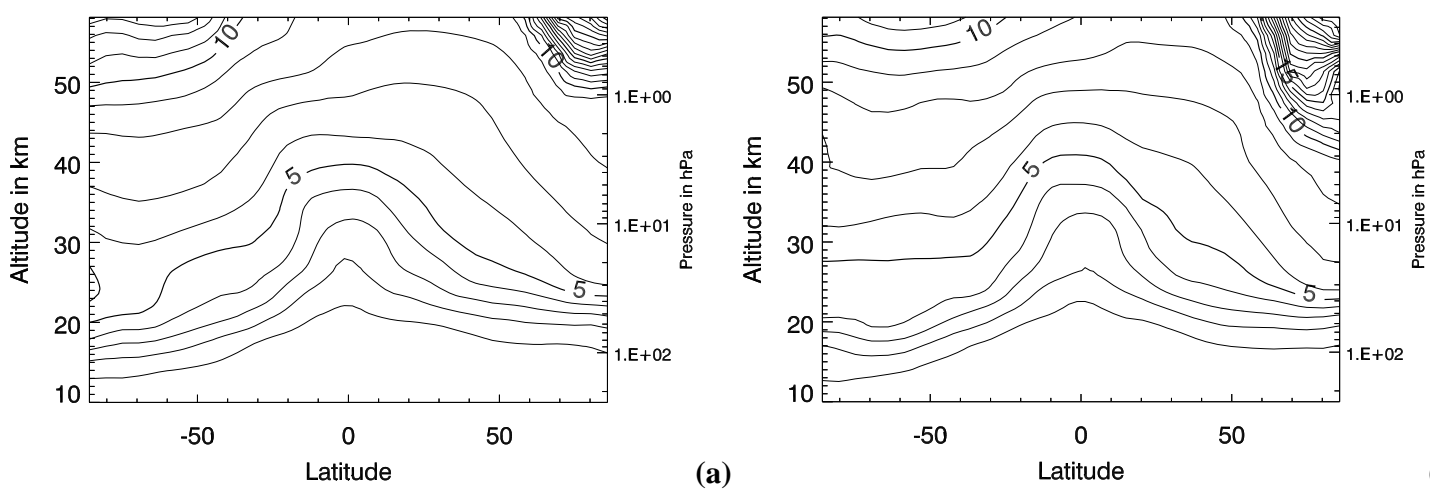

(b)
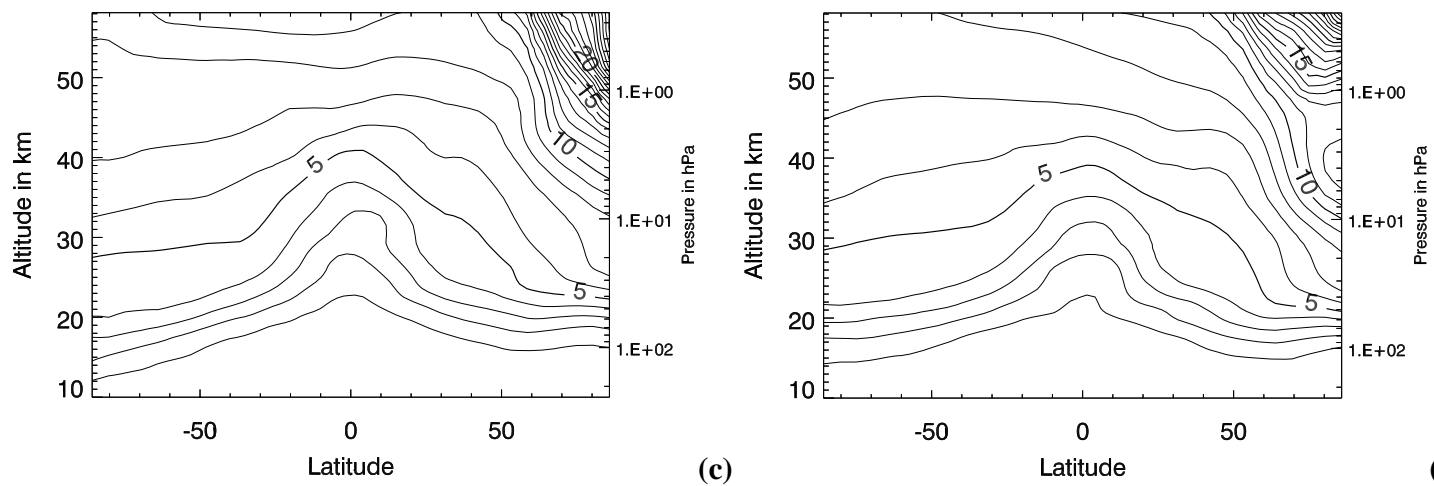

(d)

Fig. 8. Zonal mean distribution of apparent age for the DOY 300 (a), 320 (b), 340 (c) and 360 (d), as calculated from the KASIMA model. The descent of mesospheric air masses with high apparent age values can be seen already on day 300; note the local minimum in apparent age values around $2 \mathrm{hPa}$ (about $45 \mathrm{~km}$ ) on day 360 at high northern latitudes, which indicates air masses of more stratospheric origin.

latitude/longitude grid and vertically to 25 isentropic levels which extend from the surface up to $1600 \mathrm{~K}$. To consider diabatic processes, heating rates derived from the radiative transfer scheme of the SLIMCAT 3-D chemical transport model (Chipperfield, 1999) are applied.

An ensemble of trajectories was initialised on 6 March 2003 (12:00 UT) within a grid around Kiruna (latitude: $66.25^{\circ} \mathrm{N}-68.75^{\circ} \mathrm{N}$, longitude: $20.0^{\circ} \mathrm{E}-22.5^{\circ} \mathrm{E}$ ) at different potential temperature $(\Theta)$ levels between $475 \mathrm{~K}$ and $840 \mathrm{~K}$ $(\sim 20-30 \mathrm{~km})$. One kilometer $(\Delta \Theta: 25-50 \mathrm{~K})$ was chosen as altitude distance between two $\Theta$-levels. In the altitude range between 24 and $27 \mathrm{~km}$, where the TRIPLE measurement showed unusual trace gas concentrations, the altitude distance was scaled down to $15 \mathrm{~K}(\sim 0.3 \mathrm{~km})$. Starting on 6 March 2003, the trajectories were calculated backward up to 1 November 2002 and forward up to 30 March 2003.

Figure 9 shows time series of the mean and the standard deviations of the potential temperature of the calculated trajectories (not all levels are shown, in order not to overload the plot). The trajectories, which were initialised on 6 March at levels below $640 \mathrm{~K}(\sim 25.2 \mathrm{~km}$, yellow line in Fig. 9), stay in the stratosphere over the whole winter. The trajectories initialised at $665 \mathrm{~K}(\sim 25.8 \mathrm{~km}$, red line in Fig. 9) enter the stratosphere on average around the end of November. At the levels above the standard deviation is very high. This indicates high variations in the origin and the transport path of the air masses. Figure 10 confirms the different origin of the air masses at the upper levels, arriving in the area around Kiruna on 6 March. Most trajectories of the levels initialised from $710 \mathrm{~K}$ to $840 \mathrm{~K}$ ( $\sim 26.9-29.9 \mathrm{~km})$ descended from the mesosphere, but there is also a large amount of air masses coming from tropical regions. A similar calculation by Rosenfield and Schoeberl (2001) for several winters between 1992 and 2000 actually showed a smaller fraction of air masses which originates in the tropics. The mesospheric part of the air masses descended into the stratosphere between end of December and mid of January. The trajectories initialised at $665 \mathrm{~K}(\sim 25.8 \mathrm{~km})$ show nearly no tropical origin, but a high mesospheric percentage entering the stratosphere between November and beginning of December. Due to the absence of tropical air, the mean age of air in this layer is expected to be higher than in the levels above and below (see Sect. 5). This layer of mesospheric air persists over the time and descends downward within the polar vortex.

The trajectory calculations can only give a qualitative view of the observed features. Mixing processes cannot be 


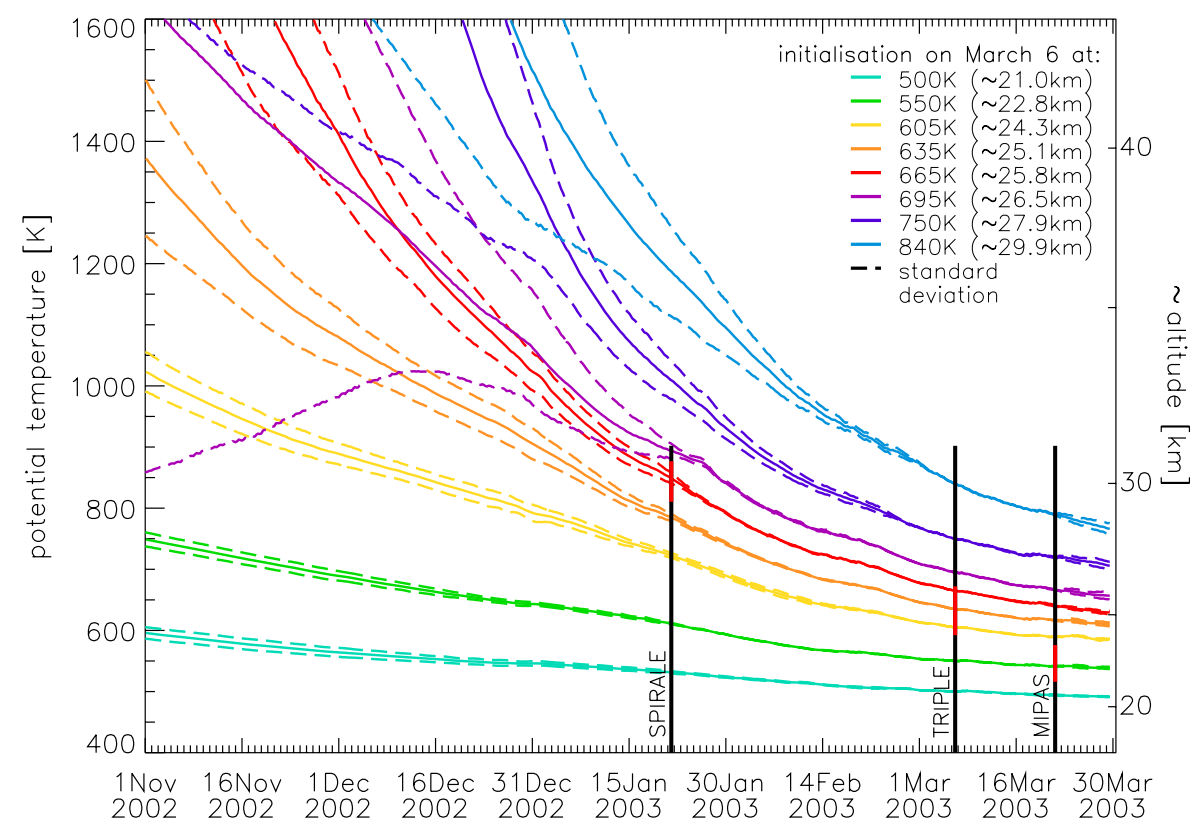

Fig. 9. Temporal evolution of potential temperature of the trajectories (mean and standard deviation) for selected initialisation levels. The black vertical lines indicate the measurement days investigated in this paper. The red segments within these black lines denote the altitude range where the observation showed a high fraction of mesospheric air. See text for more details.
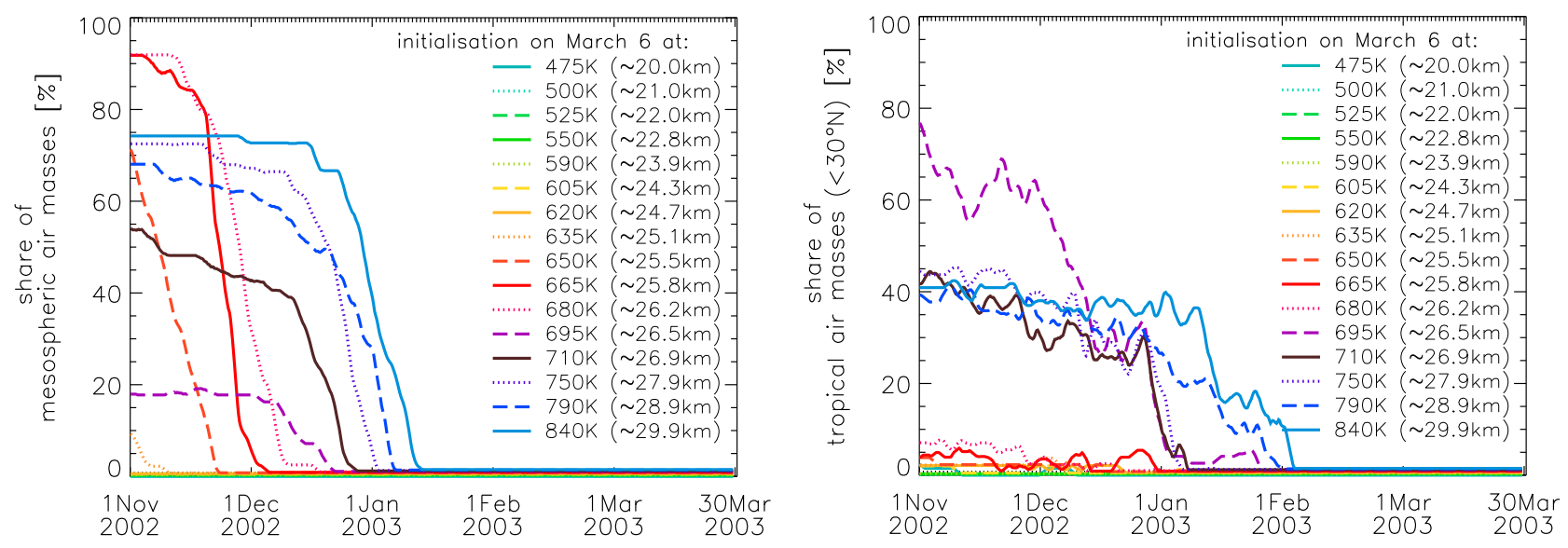

Fig. 10. Percentage of the trajectories located in the mesosphere (left-hand panel) and in the tropics (right-hand panel) over the time. Trajectories leaving the model domain trough the upper boundary $(\Theta \geq 1600 \mathrm{~K})$ considered to be of mesospheric origin. Trajectories residing at tropical latitudes $\left(<30^{\circ} \mathrm{N}\right)$ were counted as tropical air masses. Some air masses are located within the tropical mesosphere, so the sum of mesospheric and tropical percentages can be higher than $100 \%$. 
depicted with this kind of investigation. Merely, the main transport phenomena and the main temporal development can be described. As no mixing occurs in these calculations, it is expected that the absolute amount of the mesospheric fraction is overestimated in the peak, whereas it may be underestimated in the other regions. The results of the trajectory calculation fit very well the mesospheric layers observed by SPIRALE on 27 January and by TRIPLE on 6 March (Fig. 9). At the end of March the mesospheric layer within the stratosphere derived from the trajectory calculation is located around $24 \mathrm{~km}$, a little bit higher than measured by the MIPAS instrument. This result is in agreement with the small disagreement in altitude between the KASIMA model and MIPAS observations. The large fraction of tropical air masses in the backward trajectories in comparison to previous studies (Rosenfield and Schoeberl, 2001) supports the assumption that the winter 2002/2003 was extraordinary from a dynamical point of view.

\section{Discussion}

The measurements presented above show that air masses with mesospheric characteristics were present in the stratospheric polar vortex during early 2003 (January to March period). As mesospheric signatures were observed during several balloon flights (each only representing a snapshot of the stratospheric conditions) it is concluded that this must have been a rather wide spread feature. The observations give a consistent picture of a layer of mesospheric air which is transported downwards in the stratosphere, in the same time being diluted with air of stratospheric origin.

\subsection{Downward transport of mesospheric air}

The KASIMA calculations show that the mesospheric air descended mainly between November and mid December 2002. In the second half of December the air descending into the polar vortex showed apparent ages characteristic of stratospheric air. As described by Naujokat and Grunow (2003), the first mid winter warming in the lower stratosphere of the winter 2002/2003 started to develop in the second half of December, i.e. later than the descend of the mesospheric air in the model. In the upper stratosphere, a continuous warming was observed from the beginning of November until mid December. It therefore seems that the warming in late December was not responsible for the downward transport of mesospheric air, but could rather be associated with poleward transport of upper stratospheric air, in accordance with the high fraction of tropical air derived from the trajectory calculations. The general mechanisms for stratospheric warmings which was first suggested by Matsuno (1971) is that an enhanced wave forcing leads to a deceleration of the polar night jet and a simultaneous poleward meridional circulation. As air from lower latitudes is trans- ported polewards (see section on trajectory calculations under Sect. 4.4), there is descending motion below and ascending motion above at high latitudes, leading to warming of the stratosphere and a simultaneous cooling of the mesosphere (e.g. Labitzke, 1972). The downward transport and warming at high latitudes in the stratosphere is also necessary for the conservation of geostrophic equilibrium (e.g. Petzold, 1992). As the upper stratospheric air from lower latitudes descended inside the vortex, it cut off the further descent of mesospheric air into the stratosphere. This is reflected in the high fraction of air of tropical origin in the trajectories which were started above the mesospherically influenced layer. Haynes et al. (1991) showed that the pole to pole meridional circulation in the mesosphere is driven by gravity wave breaking. Plumb et al. (2002) argued that the westerly flow in the winter stratosphere of the northern hemisphere acts as a selective filter allowing only waves with an easterly phase speed to propagate upwards. The breaking of these waves leads to a westerly force which in turn leads to a poleward meridional circulation. The deceleration of the stratospheric westerly zonal wind during the stratospheric warming events in late December and January would thus let gravity waves with different phase speeds travel upward, leading to a less selective mesospheric forcing and a weaker forcing of the poleward meridional circulation in the mesosphere. This is consistent with a similar observation of mesospheric air based on observations of $\mathrm{SF}_{6}$ and $\mathrm{CO}_{2}$ measurements on 5 March 2000 (Plumb et al., 2002; Ray et al., 2002), which did not show such a layered structure but rather increasing mesospheric influence up to an altitude of about 32 to $33 \mathrm{~km}$. The 1999/2000 vortex was much more stable than the 2002/2003 vortex, the selective clipping of gravity waves in the stratosphere would thus have persisted over the winter. A fast poleward meridional transport of air has also been observed in the middle stratosphere during the major warming in late January (Kleinböhl et al., 2005). Note, however, that these air masses were outside of the polar vortex, whereas our trajectory calculations show tropically influenced air-masses inside of the polar vortex. These air masses were transported poleward above the polar vortex and descended into the vortex.

Previous simultaneous observations of $\mathrm{SF}_{6}$ and $\mathrm{CO}_{2}(\mathrm{En}-$ gel et al., 2002), which were also partly performed inside the polar vortex showed no such difference between $\mathrm{CO}_{2}$ and $\mathrm{SF}_{6}$ derived mean age values. The only previous occasion when such a large difference between $\mathrm{CO}_{2}$ and $\mathrm{SF}_{6}$ derived mean age was observed by our group was when sampling a remnant of the 1996/1997 polar vortex on 23 June in mid latitudes (Strunk et al., 2000). A balloon observation on 5 March 2000 (Ray et al., 2002; Plumb et al., 2002) also showed the influence of mesospheric air, while another observation a few days prior on 1 March 2000 showed quite good agreement between $\mathrm{CO}_{2}$-derived mean age and $\mathrm{SF}_{6}$ derived mean age (Engel et al., 2002), although both observations were made well inside the vortex. Other simultaneous observations of $\mathrm{SF}_{6}$ and $\mathrm{CO}_{2}$ during January and February 


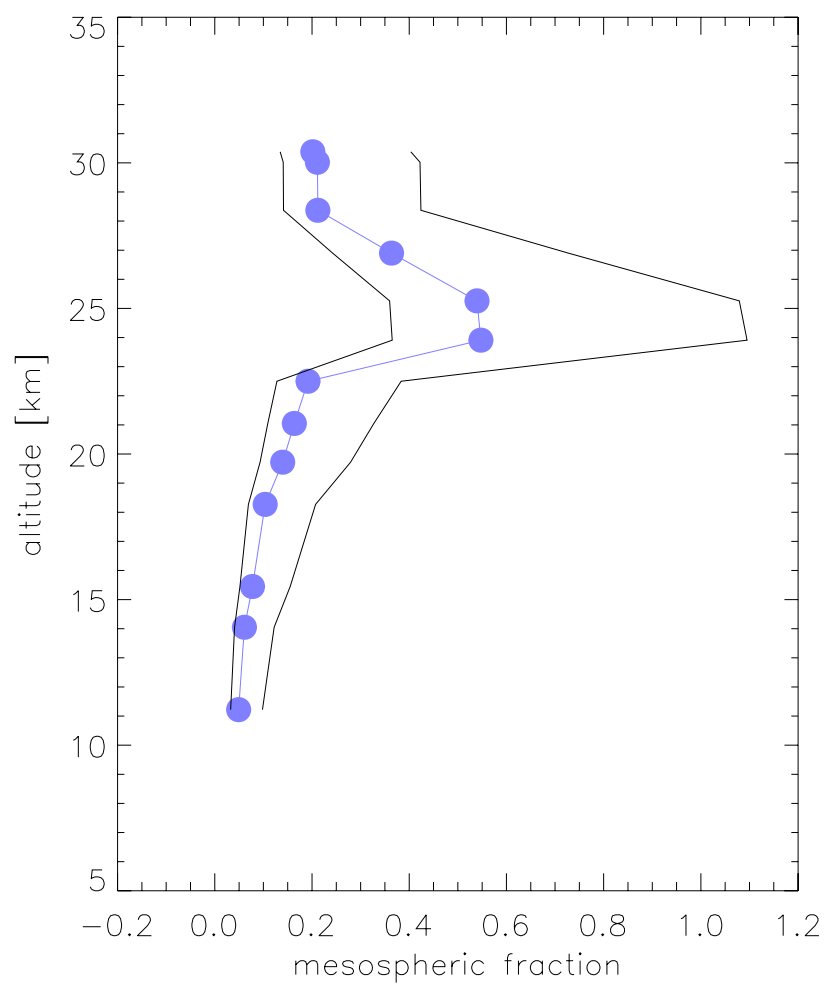

Fig. 11. Fraction of mesospheric air as calculated from the difference in mean ages derived from $\mathrm{SF}_{6}$ and $\mathrm{CO}_{2}$ observations of the cryogenic whole air sampler on 6 March, 2003. The black lines represent assumed difference of 5, resp. 15 years, while the blues dots represent the mesospheric fraction based on the assumed difference of 10 years between $\mathrm{SF}_{6}$-derived apparent age and $\mathrm{CO}_{2}$ derived mean age.

1997 did not show such a pronounced effect inside the polar vortex, although differences were noted when the air masses showed very high mean age values above 5 years (Engel et al., 2002). The influence of mesospheric air thus seems to be an irregular phenomenon which influences the vortex to largely varying extents in different years, depending on the dynamical evolution over the winter.

\subsection{The fraction of mesospheric air in the stratosphere}

As shown above, the presence of mesospheric air in the stratosphere has an important impact on the chemistry of the stratosphere and also plays an important role in many studies where tracers or tracer-tracer correlations are used to infer chemical ozone loss or mixing processes. We therefore try to quantify the fraction of mesospheric air which must have been present in the observed air masses, based on the observations on 6 March 2003. We assume that the mean age of air derived from the $\mathrm{CO}_{2}$ observations is not affected by chemical processes, as the photolysis of $\mathrm{CO}_{2}$ in the mesosphere is a reversible process ( $\mathrm{CO}$ is oxidised back to $\mathrm{CO}_{2}$ ). This is supported by the observation of several hundreds of $\mathrm{ppb}$ of $\mathrm{CO}$

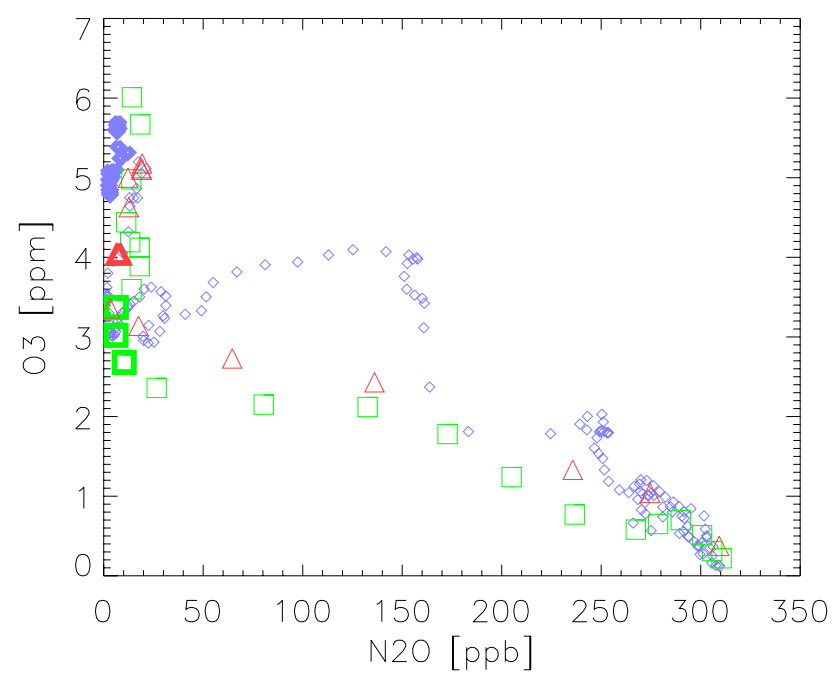

Fig. 12. $\mathrm{N}_{2} \mathrm{O}$ - ozone correlations derived from the three balloon observations. The small blue diamonds represent the SPIRALE observations of 21 January, the red triangles are BONBON observations from 6 March and the green squares are MIPAS observations from 20/21 March 2003. The mesospheric part of the correlaton (based on the respective tracers as explained in Sect. 3) is shown as bold symbols.

in January and only about 200 in early March. Assuming that the 200 ppb of CO observed on 6 March 2003 stem entirely from the photolysis of $\mathrm{CO}_{2}$, this would result in an overestimation of the $\mathrm{CO}_{2}$-derived mean age of less than 2 months. We assume that the mean age derived from the stratospheric observations of $\mathrm{SF}_{6}\left(\Gamma_{\mathrm{SF} 6, \text { obs }}\right)$ and $\mathrm{CO}_{2}\left(\Gamma_{\mathrm{CO}_{2}, \text { obs }}\right)$ is produced by a mixture of stratospheric air (with a fraction of $f_{\text {strat }}$ ) which is unaffected by mesospheric processes and has mixing ratios of $\mathrm{SF}_{6}$ and $\mathrm{CO}_{2}$ which would give consistent mean age values $\left(\Gamma_{\text {Strat }}\right)$ and a fraction of mesospheric air $\left(\mathrm{f}_{\mathrm{mes}}\right)$, which is affected by loss of $\mathrm{SF}_{6}$. The apparent mean age values derived from the $\mathrm{SF}_{6}$ transported from the mesosphere would be $\Gamma_{\text {app,mes }}$, the true mean age of air entering from the mesosphere would be $\Gamma_{\text {mes. }}$. If we neglect the small loss of $\mathrm{CO}_{2}$ in the mesospheric air we can write the following equations for the mean age values determined from $\mathrm{SF}_{6}$ and $\mathrm{CO}_{2}$ in the stratosphere:

$\Gamma_{\mathrm{SF}_{6}, \mathrm{obs}}=f_{\text {strat }} \times \Gamma_{\text {Strat }}+f_{\text {mes }} \times \Gamma_{\text {app,mes }}$

$\Gamma_{\mathrm{CO}_{2}, \text { obs }}=f_{\text {strat }} \times \Gamma_{\text {Strat }}+f_{\text {mes }} \times \Gamma_{\text {mes }}$.

Subtracting Eq. (2) from Eq. (1) and solving for $\mathrm{f}_{\text {mes }}$ yields

$f_{\text {mes }}=\frac{\Gamma_{\mathrm{SF}_{6}, \mathrm{obs}}-\Gamma_{\mathrm{CO}_{2}, \mathrm{obs}}}{\Gamma_{\mathrm{app}, \mathrm{mes}}-\Gamma_{\mathrm{mes}}}$.

In order to derive the fraction of mesospheric air, it is thus necessary to know the difference in mesospheric values of apparent age and of mean age. We have chosen to take this value from the model calculations of KASIMA. As can 
be seen from Fig. 8, apparent age in the vicinity of the stratopause (about $50 \mathrm{~km}$ altitude) shows a large range of values, between about 10 and 20 years. Typical mean age values in the upper stratosphere and lower mesosphere are estimated to be on the order of 5-6 years. We have therefore chosen to use a mean value of about 10 years as the difference between mean age and apparent age for further calculations, knowing that all results based on this value can only represent rough estimates of the amount of mesospheric air in the stratosphere. As a sensitivity study we have also performed the calculation assuming 5 and 15 years as a difference between apparent age and true mean age for mesospheric air entering the stratosphere. The vertical profile of the mesospheric fraction of the air calculated in this way is shown in Fig. 11, where the thin lines represent the profiles based on apparent age difference of 5 and 15 years for mesospheric air entering the stratosphere.

The largest fraction of mesospheric air is calculated around $25 \mathrm{~km}$ altitude. Depending on the assumed apparent difference in age for mesospheric air entering the stratosphere, a fraction between $36 \%$ (assuming a difference of 15 years), 54\% (assuming a difference of 10 years) and $108 \%$ (assuming a difference of 5 years) is calculated. The calculation of a fraction of $108 \%$ shows that the choice of 5 years of apparent age difference for mesospheric air entering the stratosphere is obviously to low, as the observed air mass showed a difference between apparent age and mean age from $\mathrm{CO}_{2}$ of about 5.5 years. A fraction above 1 should thus be interpreted as undiluted mesospheric air within the limits of uncertainty. Based on the assumptions stated above, the air mass observed at $30 \mathrm{~km}$ altitude had a mesospheric fraction of $20(14-41) \%$, whereas the air observed in the lowest part of the stratosphere around $11 \mathrm{~km}$ altitude would have a fraction of 3 to $10 \%$ of mesospheric air. As can be seen from Fig. 8, the model predicts a large variability of apparent age values with altitude and latitude. It is therefore not possible to extrapolate these results to the entire vortex or attempt to calculate the amount of mesospheric air in the vortex. It is clear, however, that in order to explain significant amounts of mesospheric air in the stratosphere, because of the low pressure at the stratopause very large volumes of mesospheric air must have been transported into the stratosphere. Plumb et al. (2002) noted that in their model, the mesosphere was flushed completely during a single winter. One can thus estimate that the entire mesosphere is flushed into the stratosphere twice per year (once during northern hemisphere winter, once during southern hemisphere winter). If this quantity of air was mixed over the entire stratosphere above $100 \mathrm{hPa}$, it would - assuming a mean stratopause pressure of $0.15 \mathrm{hPa}$ - correspond to a mesospheric input of about $0.3 \%$ of the air in this layer per year. Therefore, we expect the influence of mesospheric $\mathrm{SF}_{6}$ loss to be low on mid latitude age of air investigations based on $\mathrm{SF}_{6}$ observations. A significant influence of the mesospheric loss of $\mathrm{SF}_{6}$ on mean age determination should thus only be visible, if the mesospheric air is confined to an isolated region of the stratosphere, like e.g. the polar vortex.

\subsection{Ozone $\mathrm{N}_{2} \mathrm{O}$ correlations}

As noted in the introduction, mesospheric air masses have very different chemical characteristics from stratospheric air masses. In particular, the anti correlation between $\mathrm{N}_{2} \mathrm{O}$ and ozone in the stratosphere, changes to a correlation in the mesosphere. The presence of mesospheric air in the stratosphere, is thus expected to influence studies of ozone loss based on correlation analysis. This method to derive chemical ozone loss has recently been reviewed by Müller et al. (2005). In their study, however, the presence of large amounts of mesospheric air was not considered. As shown above, the fraction of mesospheric air in such mesospheric intrusions may be as high as $50 \%$. Figure 12 shows the correlation between $\mathrm{N}_{2} \mathrm{O}$ and ozone observed during the three balloon flights. For all flights, the mesospheric data points are shown as bold symbols. There is no clear difference between these data points and the other data. However, as indicated above, the mesospheric influence was not confined to these regions, which makes it difficult to assess the difference between chemical ozone loss in the stratosphere and naturally ozone poor mesospheric air. A more detailed study, including full chemistry model runs would be needed to investigate the question of the influence of mesospheric air on $\mathrm{N}_{2} \mathrm{O}-$ ozone correlations and ozone loss deduced from these.

\section{Conclusions}

We have shown that air which has been transported from the mesosphere was observed in the Arctic stratospheric vortex in early 2003. This was observed during 3 balloon flights, based on different tracers or combinations of tracers. The mesospherically influenced air propagated downwards with time. It was observed above $30 \mathrm{~km}$ altitude in late January, as a layer centred around $25 \mathrm{~km}$ altitude in early March and around $22 \mathrm{~km}$ in late March. Model calculations show that the descent of mesospheric air occurred during November and December 2002. During the second half of December, when the first minor midwinter warming occurred, air of mainly stratospheric origin was transported polewards in the upper stratosphere and beneath this a layer of mesospheric air was cut off and descended further inside the vortex. The KASIMA model is able to reproduce the vertical distribution of mesospherically influenced air on 6 March. The model also calculates the correct order of magnitude of $\mathrm{SF}_{6}$ derived apparent age. For the MIPAS balloon flight on 20/21 March 2003 a qualitative agreement is found, whereas there is less good agreement on 21 January 2003, probably due to the different mesospheric tracers between model and observation. Long term trajectory calculations using the heating rates calculated for the SLIMCAT model are also able to reproduce 
the layered structure. These calculations also show, that a large fraction of the air above the mesospherically influenced layer was of tropical origin, corroborating the interpretation that air from lower latitudes was transported polewards during the minor warming at the end of December 2002, thereby cutting off the descending mesospheric air. Based on assumptions about the difference between apparent age and true mean age for mesospheric air entering the stratosphere, we estimate that the fraction of mesospheric air in the layer observed on 6 March must have been more than 36\%. Even at the lowest altitudes (samples taken at $11.2 \mathrm{~km}$ altitude) observed on 6 March, mesospherically influenced air must have been present. We estimate the fraction of mesospheric air here to be between 3 and $10 \%$.

The clear evidence that mesospheric air was mixed with stratospheric air inside the Arctic polar vortex during the winter 2002/2003 is an important finding, which must be considered when using correlation studies to derive denitrification or ozone loss. It is also clear from this kind of observations, that for models to correctly simulate stratospheric polar ozone chemistry, the mesosphere must be included. For example a comparison between observed an modelled passive ozone by Konopka et al. $\left(2006^{1}\right)$ showed that there were large losses of ozone in the polar vortex in early 2003 which are attributed to chemical ozone depletion due to enhanced $\mathrm{NO}_{\mathrm{y}}$ values, which are in part of mesospheric origin.

Acknowledgements. The balloon launches discussed in this study were performed by the CNES balloon launch team, under the lead of the late P. Faucon. We would like to thank P. Faucon for his friendship and professional co-operation over many years and to acknowledge the excellent balloon launch operations during the ENVISAT validation campaign. Funding by ESA, CNES and DLR for the balloon operations is gratefully acknowledged.

Edited by: M. Dameris

\section{References}

Andrews, A. E., Boering, K. A., Daube, B. C., Wofsy, S. C., and Loewenstein, M.: Mean ages of stratospheric air derived from in situ observations of $\mathrm{CO}_{2}, \mathrm{CH}_{4}$ and $\mathrm{N}_{2} \mathrm{O}$, J. Geophys. Res., 106(D23), 32 295-32 314, 2001.

Bauer, R., Engel, A., Franken, H., Kulessa, G., Schiller, C., Schmidt, U., Borchers, R., and Lee, J.: Monitoring the vertical structure of the arctic polar vortex over northern Scandinavia during EASOE: regular $\mathrm{N}_{2} \mathrm{O}$ profile observations, Geophys. Res. Lett., 21, 1211-1214, 1994.

Chipperfield, M. P.: Multiannual simulations with a threedimensional chemical transport model, J. Geophys. Res., 104(D1), 1781-1806, 1999.

Conway, T. J., Tans, P. P., Waterman, L. W., Thoning, K. W., Kitzis, D. R., Masarie, K. A., and Zhang, N.: Evidence for interannual variability of the carbon cycle from the National Oceanic and Atmospheric Administration/Climate Monitoring and Diagnostics Laboratory Global Air Sampling Network, J. Geophys. Res., 99(D11), 22 831-22 855, 1994.
Elkins, J. W., Thompson, T. M., Swanson, T. H., Butler, J. H., Hall, B. D., Cummings, S. O., Fisher, D. A., and Raffo, A. G.: Decrease in the growth rates of atmospheric chlorofluorocarbons 11 and 12, Nature, 364, 780-783, 1993.

Engel, A., Schmidt, U., and Stachnik, R. A.: Partitioning between chlorine reservoir species deduced from observations in the Arctic winter stratosphere, J. Atmos. Chem., 27, 107-126, 1997.

Engel, A., Strunk, M., Müller, M., Haase, H.-P., Poss, C., Levin, I., and Schmidt, U.: The temporal development of total chlorine in the high latitude stratosphere based on reference distributions of mean age derived from $\mathrm{CO}_{2}$ and $\mathrm{SF}_{6}$, J. Geophys. Res., 107, 4136, doi:10.1029/2001JD000584, 2002.

Fahey, D. W., Solomon, S., Kawa S. R., Loewenstein, M., Podolske, J. R., Strahan, S. E., and Chan, K. R.: A diagnostic for denitrification in the winter polar stratosphere, Nature, 345, 698-702, 1990.

Fisher, M., O’Neill, A., and Sutton, R.: Rapid descent of mesospheric air into the stratospheric polar vortex, Geophys. Res. Lett., 20, 1267-1270, 1993.

Friedl-Vallon, F., Maucher, G., Kleinert A., Lengel, A., Keim, C., Oelhaf, H., Fischer, H., Seefeldner, M., and Trieschmann, O.: Design and characterization of the balloon-borne Michelson Interferometer for Passive Atmospheric Sounding, Appl. Opt., 43, 3335-3355, 2004.

Geller, L. S., Elkins, J. W., Lobert, J. M., Clarke, A. D., Hurst, D. F., Butler, J. H., and Myers, R. C.: Tropospheric SF 6 : Observed latitudinal distribution and trends, derived emissions and interhemispheric exchange time, Geophys. Res. Lett., 24, 675-678, 1997.

Greenblatt, J. B., Joost, H. J., Loewenstein, M., et al.: Tracer-based determination of vortex descent in the 1999/2000 Arctic winter, J. Geophys. Res., 107, 8279, doi:10.1029/2001JD000937, 2002.

Hall, T. M. and Plumb, R. A.: Age as a diagnostic of stratospheric transport, J. Geophys. Res., 99(D1), 1059-1070, 1994.

Hall, T. M. and Waugh, D. W.: Influence of nonlocal chemistry on tracer distributions: inferring mean age of air from $\mathrm{SF}_{6}$, J. Geophys. Res., 103(D11), 13 327-13 336, 1998.

Haynes, P. H., Myers, C. J., McIntyre, M. E., Shappard, T. G, and Shine, K. P.: On the downward control of extratropical diabatic circulations by eddy-induced mean zonal forces, J. Atmos. Sci., 48, 651-678, 1991.

Höpfner, M., Oelhaf, H., Wetzel, G., Friedl-Vallon, F., Kleinert, A., Lengel, A., Maucher, G., Nordmeyer, H., Glatthor, N., Stiller, G., von Clarmann, T., Fischer, H., Kröger, C., and Deshler, T.: Evidence of scattering of tropospheric radiation by PSCs in mid-IR limb emission spectra: MIPAS-B observations and KOPRA simulations, Geophys. Res. Lett., 29(8), 1278, doi:10.1029/2001GL014443, 2002.

Huret, N., Pirre, M., Hauchecorne, A., Robert, C., and Catoire, V.: On the vertical structure of the stratosphere at mid-latitude during the first stage of the polar vortex formation and in the polar region in the presence of a large mesospheric descent, J. Geophys. Res., in press, 2006.

Khalil, M. A. K. and Rasmussen, R. A.: Carbon monoxide in the earth's atmosphere - Indications of a global increase, Nature, 332, 242-245, 1988.

Khalil, M. A. K. and Rasmussen, R. A.: Global increase of atmospheric molecular hydrogen, Nature, 347, 743-745, 1990.

Kleinböhl, A., Kuttippurath, J., Sinnhuber, M., Sinnhuber, B.-M., 
Küllmann, H., Künzi, K., and Notholt, J.: Rapid meridional transport of tropical airmasses to the Arctic during the major stratospheric warming in January 2003, Atmos. Chem. Phys., 5, 1291-1299, 2005,

SRef-ID: 1680-7324/acp/2005-5-1291.

Kondo, Y., Koike, M., Engel, A., Schmidt, U., Müller, M., Sugita, T., Kanzawa, H., Nakazawa, T., Aoki, S., Irie, H., Toriyama, N., Suzuki, T, and Sasano, Y.: $\mathrm{NO}_{\mathrm{y}}-\mathrm{N}_{2} \mathrm{O}$ correlation observed inside the Arctic vortex in February 1997: Dynamical and chemical effects, J. Geophys. Res., 104, 8215-8224, 1999.

Kouker, W., Beck, A., Fischer, H., and Paetzold, K.: Downward transport in the upper stratosphere during the minor warming in February 1979, J. Geophys. Res., 100, 11 069-11 084, 1995.

Kouker, W., Offermann, D., Küll, V., Reddmann, T., Ruhnke, R., and Franzen, A.: Streamers observed by the CRISTA experiment and simulated in the KASIMA model, J. Geophys. Res., 104(D13), 16405-16418, 1999.

Labitzke, K.: Temperature changes in the mesosphere and stratosphere connected with circulation changes in winter, J. Atmos. Sci., 29(4), 756-766, 1972.

LeTexier, H., Solomon, S., and Garcia, R. R.: The role of molecular hydrogen and methane oxidation in the water vapor budget of the stratosphere, Quart. J. Roy. Meteor. Soc., 11, 281-295, 1988.

López-Valverde, M. A., López-Puertas, M., Remedios, J. J., Rodgers, C. D., Taylor, F. W., Zipf, E. C., and Erdman, P. W.: Validation of measurements of carbon monoxide from the Improved Stratospheric and Mesospheric Sounder, J. Geophys. Res., 101, 9929-9955, 1996.

Maiss, M. and Levin, I.: Global increase of $\mathrm{SF}_{6}$ observed in the atmosphere, Geophys. Res. Lett., 21, 569-572, 1994.

Matsuno, T.: A dynamical model of the stratospheric sudden warming, J. Atmos. Sci., 28, 1479-1494, 1971.

Moreau G., Robert, C., Catoire V., Camy-Perret, C., Huret, N., Pirre, M., Pomathiod, L., and Chartier, M.: SPIRALE: A multispecies in situ balloon-borne instrument with six tunable diode laser spectrometers, Appl. Optics, 44, 5972-5989, 2005.

Müller, R., Crutzen, P. J., Grooß, J.-U., Brühl, C., Russell, J. M., Gernandt, H., McKenna D. S., and Tuck, A. F.: Severe chemical ozone loss in the Arctic during the winter 1995-96, Nature, 389, 709-712, 1997.

Müller, R., Schmidt, U., Engel, A., McKenna, D. S., and Proffitt, M. H.: The $\mathrm{O}_{3} / \mathrm{N}_{2} \mathrm{O}$ relation from balloon-borne observations as a measure of Arctic ozone loss in 1991/92, Q. J. R. Meteorol. Soc., 127, 1389-1412, 2001.

Naujokat, B. and Grunow, K.: The stratospheric Arctic winter 2002/03: balloon flight planning by trajectory calculations, Proceedings of the 16th ESA Symposium on European Rocket and Balloon Programmes and Related Research, St. Gallen 2003 (ESA SP-530), 421-425, 2003.

Petzold, K.: Dynamik der Stratosphärenerwärmungen , Promet, 22, 90-96, 1992.

Plumb, R. A., Waugh, D. W., and Chipperfield, M. P.: The effects of mixing on tracer relationships in the polar vortices, J. Geophys. Res., 105, 10 047-10 062, 2000.

Plumb, R. A., Heres, W., Neu, J. L., Mahowald, N., del Corral, J., Toon, G. C., Ray, E., Moore F., and Andrews, A. E.: Global tracer modeling during SOLVE: high latitude descent and mixing, J. Geophys. Res., 107, 8309, doi:10.1029/2001JD001023, 2002 (printed 108(D5), 2003).
Podolske, J. R., Loewenstein, M., Strahan, S. E., and Chan, K. R.: Stratospheric Nitrous Oxide distribution in the Southern Hemisphere, J. Geophys. Res., 94, 16767-16 772, 1989.

Proffitt, M. H., Margitan, J. J., Kelly, K. K., Loewenstein, M., Podolske, J. R., and Chan, K. R.: Ozone loss in the Arctic polar vortex inferred from high altitude aircraft measurements, Nature, 347, 31-36, 1990.

Ravishankara, A. R., Solomon, S., Turniseed, A. A., and Warren, R. F.: Atmospheric lifetimes of long-lived halogenated species, Science, 259, 194-199, 1993.

Ray, E. A., Moore, F. L., Elkins J. W., Hurst, D. F., Romashkin, P. A., Dutton, G. S., and Fahey, D. W.: Descent and mixing in the 1999-2000 northern polar vortex inferred from in situ tracer measurements, J. Geophys. Res., 107, 8285, doi:10.1029/2001JD000961, 2002.

Reddmann, T., Ruhnke, R., and Kouker, W.: Three-dimensional model simulations of $\mathrm{SF}_{6}$ with mesospheric chemistry, J. Geophys. Res., 106, 14 525-14 537, 2001.

Reimer, E. and Scherer, B.: An operational meteorological diagnostic system for regional air pollution analysis and long term modeling, Air pollution modeling and its application IX, Proceedings of the Ninetenth NATO/CCMS International Technical Meeting on Air pollution modeling and its application, Sept., 29-Oct., 4, 1991, Crete, Greece, 1992

Rinsland, C. P., Salawitch, R. J., Gunson, M. R., Solomon, S., Zander, R., Mahieu, E., Goldman, A., Newchurch, M. J., Irion, F. W., and Chang, A. Y.: Polar stratospheric descent of NOy and CO and Arctic denitrification during winter 1992-1993, J. Geophys. Res., 104, 1847-1861, 1999.

Rosenfield, J. E. and Schoeberl, M. R.: On the origin of polar vortex air., J. Geophys. Res., 106(D24), 33 485-33 497, 2001.

Schmidt, U., Kulessa, G., Klein, E., Röth, E.-P., Fabian, P., and Borchers, R.: Intercomparison of balloon-borne cryogenic whole air samplers during the MAP/GLOBUS 1983 campaign, Planet. Space Sci. 35, 647-656, 1987.

Siskind, D. E., Bacmeister, J. T., Summers, M. E., and Russell, J. M., Two-dimensional model calculations of nitric oxide transport in the middle atmosphere and comparison with Halogen Occultation Experiment data, J. Geophys. Res., 102(D3), 3527-3546, 1997.

Solomon, S., Garcia, R. R., Olivero, J. J., Bevilaqua, R. M., Schwartz, P. R., Clancy, R. T., and Muhelman D. O.: Photochemistry and transport of carbon monoxide in the middle atmosphere, J. Atmos. Sci., 42, 1072, 1985.

Strunk, M., Engel, A., Schmidt, U., Volk, C. M., Wetter, T., Levin I., and Glatzel-Mattheier, $\mathrm{H} .: \mathrm{CO}_{2}$ and $\mathrm{SF}_{6}$ as stratospheric age tracers: consistency and the effect of mesospheric loss, Geophys. Res. Lett., 27, 341-344, 2000.

Volk, C. M., Elkins, J. W., Fahey, D. W., Dutton, G. S., Gilligan, J. M., Loewenstein, M., Podolske, J. R., Chan, K. R., and Gunson, M. R.: Evaluation of source gas lifetimes from stratospheric observations, J. Geophys. Res., 102, 25 543-25 564, 1997.

Waugh, D. W. and Hall, T. M.: Age of stratospheric air: Theory, observations, and models, Rev. Geophys., 40, 1010, doi:10.1029/2000RG000101, 2002.

Wetzel, G., Oelhaf, H., Ruhnke, R., Friedl-Vallon, F., Kleinert, A., Kouker, W., Maucher, G., Reddmann, Th., Seefeldner, M., Stowasser, M., Trieschmann, O., von Clarmann, T., and Fischer, $\mathrm{H}$.: $\mathrm{NO}_{y}$ partitioning and budget and its correlation with $\mathrm{N}_{2} \mathrm{O}$ in 
the Arctic vortex and in summer mid-latitudes in 1997, J. Geophys. Res., 107(D16), 4280, doi:10.1029/2001JD000916, 2002.

Woyke, T., Müller, R., Stroh, F., McKenna, D. S., Engel, A., Margitan, J. J., Rex, M., and Carslaw, K. S.: A test of our understanding of the ozone chemistry in the Arctic polar vortex based on in situ measurements of $\mathrm{ClO}, \mathrm{BrO}$, and O3 in the 1994/1995 winter, J. Geophys. Res., 104(D15), 18 755-18 768, 1999.
Zöger, M., Afchine, A., Eicke, N., Gerhard, M.-T., McKenna, D. S., Mörschel, U., Schmidt, U., Tan, V., Tuitjer, F., Woyke, T., and Schiller, C.: FISH: A novel family of balloonborne and airborne Lyman-a photofragment fluorescence hygrometers, J. Geophys. Res., 104, 1807-1816, 1999. 